\title{
FIIISA
}

\section{Global and Regional \\ Greenhouse Gas Emissions \\ Scenarios}

Tom Kram, Tsuneyuki Morita, Keywan Riahi, R. Alexander Roehrl, Sascha van Rooijen, Alexei Sankovski, and Bert de Vries

RR-00-22

September 2000

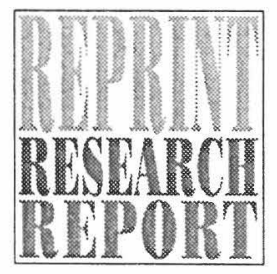





\section{Global and Regional Greenhouse Gas Emissions Scenarios}

Tom Kram, ${ }^{1}$ Tsuneyuki Morita, ${ }^{2}$ Keywan Riahi, ${ }^{3}$ R. Alexander Roehrl, ${ }^{3}$ Sascha van Rooijen, ${ }^{1}$ Alexei Sankovski, ${ }^{4}$ and Bert de Vries $^{5}$

${ }^{1}$ Netherlands Energy Research Foundation, Petten, The Netherlands

${ }^{2}$ National Institute for Environmental Studies, Tsukuba, Ibaraki, Japan

${ }^{3}$ International Institute for Applied Systems Analysis, Laxenburg, Austria

${ }^{4}$ ICF Kaiser International, Washington, DC, USA

${ }^{5}$ RIVM, Bilthoven, The Netherlands

RR-00-22

September 2000

Reprinted from Technological Forecasting and Social Change, 63, 335-371 (2000). 
Research Reports, which record research conducted at IIASA, are independently reviewed before publication. Views or opinions expressed herein do not necessarily represent those of the Institute, its National Member Organizations, or other organizations supporting the work.

Reprinted from Technological Forecasting and Social Change, 63, 335-371 (2000).

Copyright (c) 2000, with permission from Elsevier Science Inc.

All rights reserved. No part of this publication may be reproduced or transmitted in any form or by any means, electronic or mechanical, including photocopy, recording, or any information storage or retrieval system, without permission in writing from the copyright holder. 


\title{
Global and Regional Greenhouse Gas Emissions Scenarios
}

\author{
TOM KRAM, TSUNEYUKI MORITA, KEYWAN RIAHI, \\ R. ALEXANDER ROEHRL, SASCHA VAN ROOIJEN, \\ ALEXEI SANKOVSKI, and BERT DE VRIES
}

ABSTRACT

This article presents a set of 30 greenhouse gas (GHG) emissions scenarios developed by six modeling teams. The scenarios describe trajectories up to 2100 by four world regions. Today the distribution of both income and GHG emissions is very unbalanced between various world regions. Furthermore, the relative importance of individual gases and sources of emission differ from region to region. A feature shared by all scenarios is higher growth rates of population, income and GHG emissions in the current developing countries (DEV) than in industrialized countries (IND). Today the DEV regions account for about $46 \%$ of all emissions, but by 2100 no less they contribute $67-76 \%$ of the global total. By that same year the total income generated in the DEV regions reaches $58-71 \%$ from only $16 \%$ in 1990 . As a result of these two developments, GHG emissions per unit of income converge over time. Carbon emitted from fossil fuel use remains the primary source of GHG emissions over the next century; by $2100 \mathrm{CO}_{2}$ makes up 70 to $80 \%$ of total GHG emissions. The role of sulfur warrants special attention. Contrary to many earlier studies, all scenarios presented here assume that sulfur emissions are controlled in all regions sooner or later, and to various degrees. As sulfur plays a role in cooling of the atmosphere through formation of sulfate aerosols, a local effect, this abatement constitutes a relative local warming effect. The decrease of sulfur emissions is already observed the IND regions, and is expected also in ASIA after an initial rise. (c) 2000 Elsevier Science Inc.

\section{Introduction}

This article describes a set of 30 global and regional greenhouse gas (GHG) emissions scenarios that were developed by six modeling groups. According to one definition, emission scenarios should be "based on specific assumptions about key determinant" of future GHG emissions "such as population, economic growth, technological change, landuse trends or emission control policies" [1]. Therefore, the development of scenarios should cover a wide variety of topics and requires an interdisciplinary modeling approaches.

TOM KRAM and SASCHA VAN ROOIJEN are with the Netherlands Energy Research Foundation (ECN), P.O. Box 1, NL-1755 ZG Petten, The Netherlands.

TSUNEYUKI MORITA is with the National Institute for Environmental Studies in Tsukuba Ibaraki, Japan.

KEYWAN RIAHI and R. ALEXANDER ROEHRL are with the International Institute for Applied Systems Analysis (IIASA) in Laxenburg. Austria.

ALEXEI SANKOVSKI is with ICF Kaiser International in Washington, DC.

BERT DE VRIES is affiliated with RIVM in Bilthoven. The Netherlands.

Address correspondence to Tom Kram, Netherlands Energy Research Foundation (ECN), P.O. Box 1, NL-1755 ZG Petten, The Netherlands.

Technological Forecasting and Social Change 63, 335-371 (2000) 
The Intergovernmental Panel on Climate Change (IPCC) suggests that the main purposes of emissions scenarios are to evaluate the environmental and climatic consequences of intervening or not intervening to reduce GHGs, to examine the feasibility and costs of mitigating GHGs from different sources, and as input to negotiating possible emissions reductions for different countries and geographic regions [1]. Because GHG emissions scenarios play such an important role in the analysis of climate change, the IPCC decided in 1996 to develop a new set of scenarios that reflect the latest thinking of the scientific community and stockholders in the climate change issue. According to the terms of reference for the new scenarios, they are to be based on an extensive review and assessment of literature addressing future emissions scenarios and to encompass the full range of future global and regional emissions and their driving forces. In early 1997, an international and interdisciplinary writing team, including representatives from industrial and environmental organizations, was charged with the task of formulation the new scenarios using six different modeling approaches. In this article, we present the summary of the 30 initial, draft scenarios developed by the six modeling teams. Some of the background analysis behind these scenarios that includes the findings of the literature review, the assessment of GHG emissions ranges and the assessment of their driving forces is documented in the article by Nakicenovic et al. in this special issue. A more extensive documentation of this background review and assessment of key driving forces of GHG emissions is given in Alcamo and Nakicenovic's 1998 study [2].

Based on an extensive assessment of the literature, four different narrative storylines-A1, A2, B1, and B2-were formulated to describe the main scenario characteristics (see storylines below and Table 1). Based on these storylines six model groups developed quantitative scenarios of energy and economic development, land use, and greenhouse-gas emissions.

\subsection{BRIEF DESCRIPTION OF STORYLINES}

A1: The A1 storyline and scenario family describes a future world of very rapid economic growth, low population growth and rapid introduction of new and more efficient technology. Major underlying themes are convergence, capacity building and increased cultural and social interactions, with a substantial reduction in regional differences in per capita income. There are four different storyline variants that describe alternative structures of the energy system. In addition to the A1B (Balanced) Marker scenario the A1G (unconventional Oil and Gas), A1C (Coal) and A1T (Technology) variants were developed.

A2: The A2 storyline and scenario family describe a very heterogeneous world. The underlying theme is an emphasis on self-reliance and local identities, with an emphasis on local traditions. Population growth is high, economic development regionally oriented, and technological change relatively slow.

B1: The B1 storyline and scenario family describe a convergent world with rapid change in economic structures, 'dematerialization' and introduction of clean technologies. The emphasis is on global solutions to environmental and social sustainability, including concerted efforts for rapid technology development, dematerialization of the economy, and improving equity.

B2: The B2 storyline and scenario family describe a world in which the emphasis is on local solutions to economic, social, and environmental sustainability rather than solutions on the global scale. It is a heterogeneous world with gradual, and regionally diverse technological change, where the overall dynamics of change are guided by historical experience ('dynamics as usual'). 


\subsection{SIX MODELS, SET OF 30 SCENARIOS}

In all, the following six models were used to generate a set of 30 scenarios:

- Asian Pacific Integrated Model (AIM) from the National Institute of Environmental Studies in Japan [3];

- Atmospheric Stabilization Framework Model (ASF) from ICF Kaiser in the USA [4];

- Integrated Model to Assess the Greenhouse Effect (IMAGE) from RIVM in the Netherlands [5];

- Multiregional Approach for Resource and Industry Allocation (MARIA) from University of Tokyo in Japan [6];

- Model for Energy Supply Strategy Alternatives and their General Environmental Impact (MESSAGE) from IIASA in Austria [7]; and

- The Mini Climate Assessment Model (MiniCAM) from PNNL, in the USA [8].

These six models are representative of emissions scenario modeling approaches and different integrated assessment frameworks in the literature and include so-called top-down and bottom-up models.

For each of the four scenario storylines one scenario is designated as a characteristic representative and is called a "Marker scenario". All scenarios that correspond to one of the four storylines constitute a scenario family. The four Marker scenarios A1, A2, B1 and B2 are created by respectively AIM, ASF, IMAGE, and MESSAGE modeling groups. For detailed descriptions see Morita et al., Sankovski et al., de Vries et al., and Riahi et al. in this special issue.

It was decided by the six modeling teams to group the various regional aggregations into four "macro regions":

- OECD90 region groups together all countries members of the Organization for Economic Cooperation and Development as of 1992;

- REF region consists of countries undergoing economic reform and groups together the East and Central European countries and the Newly Independent States of the former Soviet Union;

- ASIA region stands for all non-Annex I countries ${ }^{1}$ in Asia;

- ALM region stands for rest of the world and corresponds to non-Annex I countries in Africa, Latin America, and Middle East.

The OECD90 and the REF region together correspond to the industrialized countries (IND) while the ASIA and ALM region together correspond to the developing countries (DEV).

For the purpose of this study the global and regional developments of the four Marker emission scenarios, each quantified by one of four modeling teams using its own model framework, are examined in some more detail. It is worth noting that very different emission levels and trajectories emerged from attempts to quantify the same Marker scenario by all six modeling teams. Even wider ranges are found when variants, not adhering to key input assumptions that were harmonized across many other scenarios to correspond to the development in the four Markers, were explored in certain scenarios. These ranges and variants are not covered in this paper, but will be treated in contributions of the individual modeling teams in the subsequent articles in this special issue. It must be stressed that the results of the four Marker scenario are representative

' Countries not listed in the Annex I to the UN Framework Convention on Climate Change. 
TABLE 1

Ranges of Main Scenario Driving Forces Across the Four Scenario Families

\begin{tabular}{|c|c|c|c|c|c|c|c|c|}
\hline \multirow[b]{2}{*}{$\begin{array}{l}\text { Population world } \\
\text { [billion by } 2100 \text { ] }\end{array}$} & \multicolumn{2}{|c|}{$\mathrm{A} 1$} & \multicolumn{2}{|l|}{$\mathrm{A} 2$} & \multicolumn{2}{|c|}{$\mathrm{B} 1$} & \multicolumn{2}{|c|}{$\mathrm{B} 2$} \\
\hline & Low & 7.2 & High & 15.1 & Low & 7.2 & Median & 10.4 \\
\hline \multirow{6}{*}{$\begin{array}{l}\text { Population regions } \\
\text { [billion by 2100] }\end{array}$} & OECD \% & 1.1 & OECD & 1.5 & OECD & 1.0 & OECD & 0.9 \\
\hline & REF & 3.3 & REF & 0.7 & REF & 0.3 & REF & 0.4 \\
\hline & ASIA & 2.9 & ASIA & 7.3 & ASIA & 2.9 & ASIA & 5.1 \\
\hline & ALM & 2.7 & ALM & 5.5 & ALM & 2.8 & ALM & 4.1 \\
\hline & IND & 1.4 & IND & 2.2 & IND & 1.4 & IND & 1.3 \\
\hline & DEV & 5.6 & DEV & 12.9 & DEV & 5.7 & DEV & 9.1 \\
\hline $\begin{array}{l}\text { Economic growth world } \\
\text { [average annual growth rate 1990-2100] }\end{array}$ & Very high & 2.9 & Median & 2.3 & High & 2.5 & Median & 2.2 \\
\hline \multirow{6}{*}{$\begin{array}{l}\text { Economic growth regions } \\
\text { [average annual growth rate 1990-2100] }\end{array}$} & OECD \% & 1.8 & OECD & 1.6 & OECD & 1.5 & OECD & 1.1 \\
\hline & REF & 3.1 & REF & 2.4 & REF & 2.7 & REF & 2.3 \\
\hline & ASIA & 4.6 & ASIA & 3.4 & ASIA & 4.0 & ASIA & 3.8 \\
\hline & ALM & 4.1 & ALM & 3.3 & ALM & 3.8 & ALM & 3.2 \\
\hline & IND & 2.0 & IND & 1.6 & IND & 1.6 & IND & $1.3^{3}$ \\
\hline & DEV & 4.3 & DEV & 3.2 & DEV & 3.8 & DEV & 3.5 \\
\hline $\begin{array}{l}\text { Per capita income world } \\
\text { [1.000 US } \$ 90 \text { per capita by } 2100]\end{array}$ & Very high & 74.9 & Low/Median & 16.1 & High & 46.6 & Median & 22.6 \\
\hline \multirow{6}{*}{$\begin{array}{l}\text { Per capita income regions } \\
{[1.000 \text { US } \$ 90 \text { per capita by } 2100]}\end{array}$} & OECD \% & 109.2 & OECD & 58.5 & OECD & 79.7 & OECD & 61.0 \\
\hline & REF & 100.9 & REF & 20.2 & REF & 52.2 & REF & 38.3 \\
\hline & ASIA & 71.9 & ASIA & 7.8 & ASIA & 35.7 & ASIA & 19.5 \\
\hline & ALM & 60.9 & ALM & 15.2 & ALM & 44.9 & ALM & 16.1 \\
\hline & IND & 107.3 & IND & 46.6 & IND & 72.8 & IND & 54.4 \\
\hline & DEV & 66.6 & DEV & 11.0 & DEV & 40.2 & DEV & 18.0 \\
\hline
\end{tabular}


TABLE 1

(cont'd)

\begin{tabular}{|c|c|c|c|c|}
\hline & Al & $\mathrm{A} 2$ & B1 & B2 \\
\hline Primary energy use & Very high & High & Low & Median \\
\hline \multicolumn{5}{|c|}{ Hydrocarbon resource use } \\
\hline Oil & Low to very high & Very low to median & Very low to high & Low to median \\
\hline Gas & High to very high & Low to high & Median to high & Low to median \\
\hline Coal & Median to very high & Median to high & Very low to high & Low to very high \\
\hline Land use changes & Low & Median & High & Median \\
\hline \multicolumn{5}{|c|}{ Technology improvement rates } \\
\hline Coal & High & Median & Median & Low \\
\hline Oil & High & Low & Median & Low-Median \\
\hline Gas & High & Low & Meidan & Moderately-High \\
\hline Non-fossil & High & Low & Moderately-High & Median \\
\hline
\end{tabular}


for the scenario families and cover the full range of scenario found in the literature. However, the four Markets are not the average or mean scenario for the scenario family they represent, nor the best guess or most likely development.

\section{Global Paths and Regional Distribution of Emission Scenarios}

\subsection{SUBSECTION INTRODUCTION}

This section discusses the global and regional emission trajectories ${ }^{2}$ of the four emission scenario families (A1, A2, B1, and B2). The structure of this section is as follows. Subsection 2.2 discusses the trajectories of the greenhouse gases: carbon dioxide, methane, nitrous oxide, and halocarbons and other galogenated compounds. Subsection 2.3 deals with the sulfur emission paths.

\subsection{GREENHOUSE GASES}

\subsubsection{Carbon Dioxide}

Carbon dioxide $\left(\mathrm{CO}_{2}\right)$ is the most important contributor to the enhanced radiative forcing of the atmosphere. The main sources of anthropogenic $\mathrm{CO}_{2}$ emissions are the burning of fossil fuels (coal, oil, and gas) and biomass, and the net release of carbon from changes in the terrestrial biosphere, commonly termed land-use changes. To a lesser extent, industrial activities-in particular cement production-emit $\mathrm{CO}_{2}$.

2.2.1.1. CARBON DIOXIDE EMISSIONS FROM FOSSIL FUELS AND INDUSTRY. Fossil fuels are the main source of $\mathrm{CO}_{2}$ emissions in 1990. Therefore the main determinant of future $\mathrm{CO}_{2}$ emissions is the development of energy consumption in terms of the total volume and composition. These in turn are driven by population size, level of affluence, energy resource availability, technological development, environmental concerns, and other factors. Closely related emissions from gas flaring and industrial emissions are included in this section.

The resulting emission trajectories of $\mathrm{CO}_{2}$ emissions from fossil fuel use and industrial activities for the four Markers are displayed in Fig. 1.

The high economic growth in the A1 scenario family leads to high energy demands and hence to a steep increase in $\mathrm{CO}_{2}$ emissions in the first decades. Structural changes in the energy supply side become effective only on the longer term due to the inertia caused by long-lived capital stock and existing infrastructure. In the A1-Marker a balanced approach was assumed with respect to the direction of the rapid and radical technological changes in this highly prosperous world. The population projection adopted for this scenario family declines after 2050. This A1B-Marker was explored with the AIM model. As shown in Figure 1 world emissions start to decline in the second half of the century, even though a contracting but increasingly prosperous population continues to consume more and more energy. Emissions peak around 2050 at a level 2.7 times that of 1990 and then start to fall to two times the current level by 2100: around $13 \mathrm{GtC}$. The relative contribution of the DEV region increases from $31 \%$ in the base year to $77 \%$ by 2100 .

\footnotetext{
${ }^{2}$ Because of the multi-model approach in developing the set of 30 emission scenarios, base year values for the emission scenarios do not agree. This reflects uncertainty in 1990 (and year 2000) emission values. These differences in base year imply that there is a need to standardize the scenarios. It has been decided to standardize to the 1990 and 2000 values for the four Marker scenarios, with scenarios diverging after the year 2000. In brief, the 1990 and 2000 values for the emissions were determined by averaging the values given by the unadjusted four Marker scenarios. This was done at the four region level, and then added up to obtain the standardized global totals.
} 
Fossil\&Industrial $\mathrm{CO} 2$

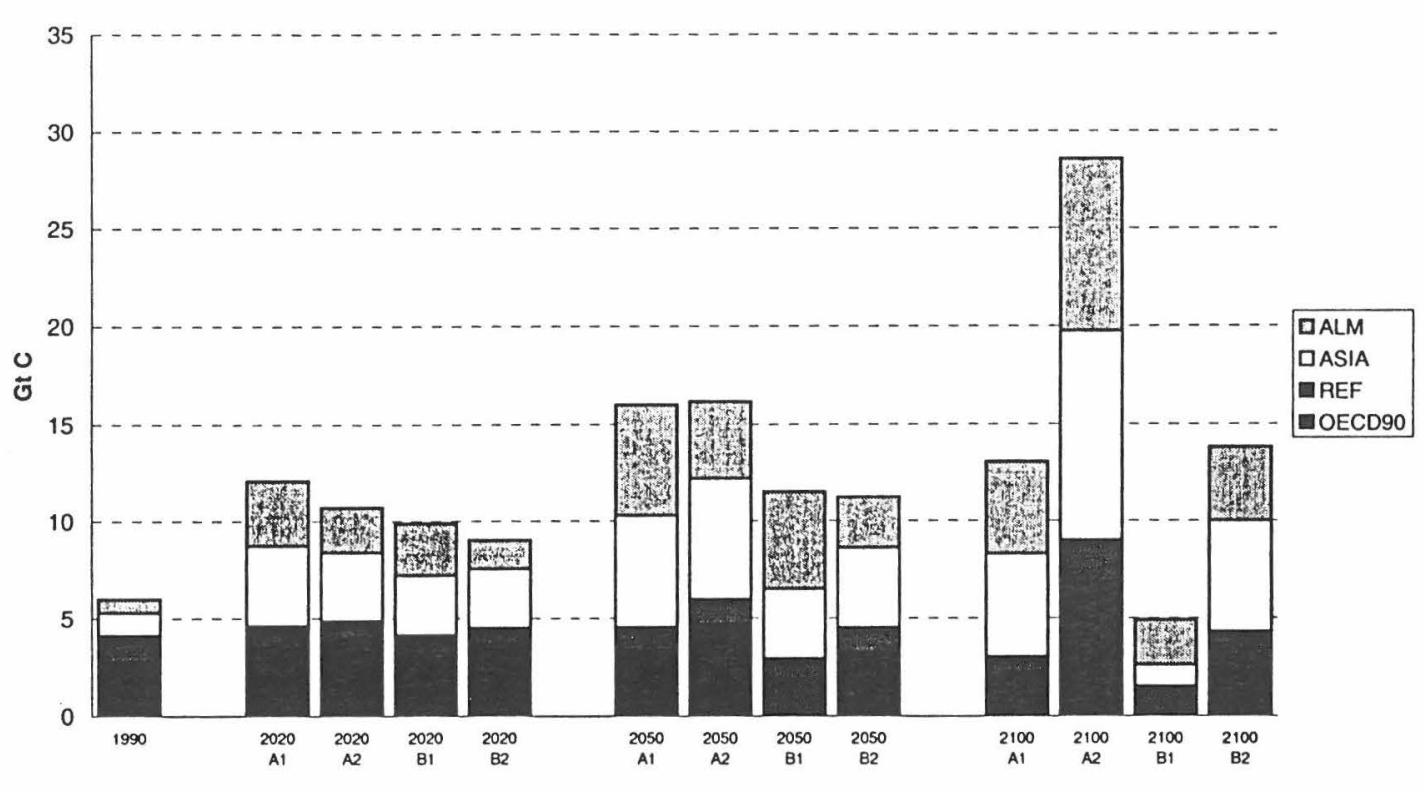

Fig. 1. Regional $\mathrm{CO}_{2}$ emissions from fossil fuels and industrial sources [GiC]. 
TABLE 2

Primary Energy Use [EJ]

\begin{tabular}{|c|c|c|c|c|c|c|c|c|}
\hline & $\begin{array}{l}\text { A IB } \\
1990\end{array}$ & $\begin{array}{c}\text { A2 } \\
1990\end{array}$ & $\begin{array}{c}\text { B1 } \\
1990\end{array}$ & $\begin{array}{c}\text { B2 } \\
1990\end{array}$ & $\begin{array}{l}\text { A1B } \\
2020 \\
\end{array}$ & $\begin{array}{c}\text { A2 } \\
2020\end{array}$ & $\begin{array}{c}\text { B1 } \\
2020\end{array}$ & $\begin{array}{c}\text { B2 } \\
2020\end{array}$ \\
\hline \multicolumn{9}{|l|}{ World } \\
\hline Coal & 85.0 & 96.6 & 100.3 & 91.1 & 144.5 & 129.3 & 138.1 & 98.3 \\
\hline Oil & 125.8 & 140.8 & 126.5 & 128.3 & 200.5 & 291.0 & 206.7 & 214.3 \\
\hline Gas & 67.6 & 74.0 & 67.3 & 70.5 & 186.5 & 125.8 & 135.2 & 150.3 \\
\hline Non-fossil & 66.6 & 17.9 & 72.5 & 61.6 & 116.3 & 48.8 & 127.2 & 102.6 \\
\hline Total & 345.0 & 329.3 & 366.6 & 351.5 & 647.8 & 594.9 & 607.2 & 565.5 \\
\hline Non-fossil (\%) & $19 \%$ & $5 \%$ & $20 \%$ & $18 \%$ & $18 \%$ & $8 \%$ & $21 \%$ & $18 \%$ \\
\hline \multicolumn{9}{|l|}{ OECD } \\
\hline Coal & 37.7 & 32.2 & 34.7 & 38.0 & 32.5 & 37.0 & 40.4 & 38.9 \\
\hline Oil & 70.0 & 77.4 & 64.2 & 72.1 & 80.8 & 116.4 & 71.8 & 90.4 \\
\hline Gas & 31.4 & 34.9 & 33.2 & 32.9 & 65.2 & 43.3 & 45.2 & 60.6 \\
\hline Non-fossil & 16.8 & 12.4 & 18.3 & 15.9 & 31.3 & 22.8 & 42.2 & 29.2 \\
\hline Total & 155.9 & 156.9 & 150.3 & 158.9 & 209.9 & 219.5 & 199.6 & 219.1 \\
\hline Non-fossil (\%) & $11 \%$ & $8 \%$ & $12 \%$ & $10 \%$ & $15 \%$ & $10 \%$ & $21 \%$ & $13 \%$ \\
\hline \multicolumn{9}{|l|}{ REF } \\
\hline Coal & 18.4 & 23.4 & 34.1 & 18.6 & 14.1 & 16.5 & 12.3 & 7.3 \\
\hline Oil & 22.2 & 18.3 & 27.8 & 20.4 & 11.6 & 15.3 & 16.0 & 18.9 \\
\hline Gas & 26.3 & 26.5 & 26.9 & 26.7 & 32.7 & 29.4 & 17.7 & 31.4 \\
\hline Non-fossil & 4.4 & 2.1 & 5.4 & 3.9 & 6.7 & 3.2 & 6.6 & 4.1 \\
\hline Total & 71.3 & 70.3 & 94.1 & 69.6 & 65.0 & 64.4 & 52.6 & 61.7 \\
\hline Non-fossil (\%) & $6 \%$ & $3 \%$ & $6 \%$ & $6 \%$ & $10 \%$ & $5 \%$ & $13 \%$ & $7 \%$ \\
\hline \multicolumn{9}{|l|}{ Asia } \\
\hline Coal & 25.8 & 36.3 & 28.3 & 29.8 & 80.4 & 62.2 & 61.0 & 47.4 \\
\hline Oil & 13.1 & 19.1 & 15.7 & 15.3 & 48.3 & 76.9 & 51.5 & 62.6 \\
\hline Gas & 3.0 & 4.0 & 3.9 & 2.8 & 26.9 & 23.8 & 40.2 & 30.9 \\
\hline Non-fossil & 29.3 & 1.6 & 30.6 & 25.7 & 30.5 & 11.4 & 43.3 & 44.0 \\
\hline Total & 71.3 & 61.0 & 78.6 & 73.6 & 186.0 & 174.2 & 195.9 & 184.9 \\
\hline Non-fossil (\%) & $41 \%$ & $3 \%$ & $39 \%$ & $35 \%$ & $16 \%$ & $7 \%$ & $22 \%$ & $24 \%$ \\
\hline \multicolumn{9}{|l|}{ ALM } \\
\hline Coal & 3.1 & 4.7 & 3.2 & 4.7 & 17.5 & 13.7 & 24.4 & 4.7 \\
\hline Oil & 20.5 & 26.0 & 18.9 & 20.5 & 59.9 & 82.5 & 67.5 & 42.4 \\
\hline Gas & 6.9 & 8.6 & 3.3 & 8.1 & 61.7 & 29.3 & 32.1 & 27.4 \\
\hline Non-fossil & 16.0 & 1.8 & 18.2 & 16.1 & 47.8 & 11.4 & 35.1 & 25.3 \\
\hline Total & 46.5 & 41.1 & 43.7 & 49.4 & 186.9 & 136.8 & 159.2 & 99.8 \\
\hline Non-fossil (\%) & $34 \%$ & $4 \%$ & $42 \%$ & $33 \%$ & $26 \%$ & $8 \%$ & $22 \%$ & $25 \%$ \\
\hline
\end{tabular}

In the OECD region the standardized fossil fuel and industrial $\mathrm{CO}_{2}$ emissions in the A1B-Marker scenario increase from $2.8 \mathrm{GtC}$ in 1990 to $3.4 \mathrm{GtC}$ in 2050 . After this peak emissions decline to $2.2 \mathrm{GtC}$. Compared to other scenarios the growth in primary energy use in the OECD region is relatively high as a result of the rapid economic development (see also Table 2). After 2050 the increasing use of primary energy goes along with declining emissions due to a combination of lower use of fossil fuels and a fossil fuel switch to gas. The share of non fossil fuels in this scenario-with rapid technological improvements-increases drastically. In 2100 the contribution of nonfossil fuel amount to $68 \%$ of the total primary energy use of the OECD. Compared to other scenarios the A1B-Marker scenario shows the largest non-fossil fuel share for the OECD region. The fossil fuel and industrial $\mathrm{CO}_{2}$ emission path of the REF region is less fluent. The base year emissions are estimated at $1.3 \mathrm{GtC}$. As a result of the restructuring of the economy the emission level declines to $1.1 \mathrm{GtC}$ in 2020. After 2020 
TABLE 2

(cont'd)

\begin{tabular}{|c|c|c|c|c|c|c|c|c|}
\hline & $\begin{array}{l}\text { A1B } \\
2050 \\
\end{array}$ & $\begin{array}{c}\text { A2 } \\
2050\end{array}$ & $\begin{array}{c}\text { B1 } \\
2050\end{array}$ & $\begin{array}{c}\text { B2 } \\
2050\end{array}$ & $\begin{array}{l}\text { A1B } \\
2100\end{array}$ & $\begin{array}{c}\text { A2 } \\
2100\end{array}$ & $\begin{array}{c}\text { B1 } \\
2100\end{array}$ & $\begin{array}{c}\text { B2 } \\
2100 \\
\end{array}$ \\
\hline \multicolumn{9}{|l|}{ World } \\
\hline Coal & 140.3 & 293.8 & 165.4 & 85.5 & 41.1 & 903.7 & 43.7 & 299.8 \\
\hline Oil & 181.0 & 227.7 & 228.0 & 227.1 & 107.0 & 0.5 & 98.7 & 51.9 \\
\hline Gas & 400.3 & 274.9 & 172.5 & 297.3 & 490.4 & 331.2 & 101.3 & 336.4 \\
\hline Non-fossil & 482.6 & 175.0 & 247.0 & 259.4 & 1440.6 & 481.8 & 271.6 & 669.2 \\
\hline Total & 1204.2 & 971.4 & 812.9 & 869.3 & 2079.1 & 1717.1 & 515.3 & 1357.3 \\
\hline Non-fossil (\%) & $40 \%$ & $18 \%$ & $30 \%$ & $30 \%$ & $69 \%$ & $28 \%$ & $53 \%$ & $49 \%$ \\
\hline \multicolumn{9}{|l|}{ OECD } \\
\hline Coal & 26.0 & 92.0 & 24.4 & 19.7 & 6.2 & 217.7 & 9.9 & 3.6 \\
\hline Oil & 50.6 & 49.4 & 39.8 & 65.0 & 29.3 & 0.0 & 19.0 & 16.7 \\
\hline Gas & 88.4 & 69.3 & 37.1 & 98.9 & 89.4 & 77.0 & 30.9 & 121.1 \\
\hline Non-fossil & 88.7 & 55.0 & 66.3 & 52.7 & 263.8 & 123.1 & 65.9 & 102.6 \\
\hline Total & 253.7 & 265.7 & 167.6 & 236.3 & 388.7 & 417.8 & 125.6 & 274.0 \\
\hline Non-fossil (\%) & $35 \%$ & $21 \%$ & $40 \%$ & $22 \%$ & $68 \%$ & $29 \%$ & $52 \%$ & $37 \%$ \\
\hline \multicolumn{9}{|l|}{ REF } \\
\hline Coal & 11.0 & 22.7 & 13.7 & 11.9 & 2.7 & 59.1 & 4.6 & 28.8 \\
\hline Oil & 6.7 & 20.7 & 17.8 & 19.6 & 2.2 & 0.2 & 8.4 & 0.1 \\
\hline Gas & 55.3 & 40.4 & 18.0 & 51.2 & 53.5 & 52.3 & 9.8 & 43.0 \\
\hline Non-fossil & 31.0 & 9.6 & 14.8 & 14.5 & 80.2 & 43.5 & 16.0 & 52.7 \\
\hline Total & 104.0 & 93.4 & 64.3 & 97.2 & 138.6 & 155.1 & 38.8 & 124.6 \\
\hline Non-fossil (\%) & $30 \%$ & $10 \%$ & $23 \%$ & $15 \%$ & $58 \%$ & $28 \%$ & $41 \%$ & $42 \%$ \\
\hline \multicolumn{9}{|l|}{ Asia } \\
\hline Coal & 77.5 & 134.0 & 63.9 & 48.4 & 25.1 & 355.0 & 10.4 & 179.7 \\
\hline Oil & 40.4 & 57.1 & 57.5 & 92.8 & 20.9 & 0.0 & 21.1 & 21.4 \\
\hline Gas & 107.7 & 78.6 & 59.3 & 60.6 & 184.0 & 84.2 & 24.4 & 39.1 \\
\hline Non-fossil & 148.6 & 65.0 & 92.8 & 117.2 & 520.3 & 142.0 & 98.1 & 281.1 \\
\hline Total & 374.2 & 334.8 & 273.5 & 319.0 & 750.3 & 581.2 & 154.0 & 521.3 \\
\hline Non-fossil (\%) & $40 \%$ & $19 \%$ & $34 \%$ & $37 \%$ & $69 \%$ & $24 \%$ & $64 \%$ & $54 \%$ \\
\hline \multicolumn{9}{|l|}{ ALM } \\
\hline Coal & 25.8 & 45.1 & 63.4 & 5.5 & 7.1 & 271.9 & 18.7 & 57.7 \\
\hline Oil & 83.4 & 100.5 & 112.9 & 49.7 & 54.5 & 0.3 & 50.3 & 13.7 \\
\hline Gas & 148.9 & 86.6 & 58.1 & 86.6 & 163.5 & 117.7 & 36.2 & 133.2 \\
\hline Non-fossil & 214.3 & 45.4 & 73.1 & 75.0 & 576.4 & 173.2 & 91.7 & 232.8 \\
\hline Total & 472.4 & 277.6 & 307.5 & 216.8 & 801.5 & 563.0 & 196.9 & 437.4 \\
\hline Non-fossil (\%) & $45 \%$ & $16 \%$ & $24 \%$ & $35 \%$ & $72 \%$ & $31 \%$ & $47 \%$ & $53 \%$ \\
\hline
\end{tabular}

the emission level increases due to high economic growth and increased energy demand. This development goes along with a declining population projection. In the period 2050-2100 the emissions decline again although the reason behind is very different from the earlier drop. By the year 2100 the non-fossil fuels contribute to $58 \%$ of the total primary energy use. The share of gas amount to almost $40 \%$. In the A1B-Marker scenario the fossil $\mathrm{CO}_{2}$ emission growth in the ASIA region is very high reflecting rapid economic growth and high energy demands. By 2100 the total primary energy use amounts to over ten times the 1990 level. The standardized emissions increase from $1.15 \mathrm{GtC}$ in 1990 to $5.73 \mathrm{GtC}$ in 2050 and $5.27 \mathrm{GtC}$ in 2100 . By the year 2100 the contribution of the two dominant resources non-fossil fuels and gas amount to respectively $69 \%$ and $25 \%$. In A1 the growth in energy demand in the ALM region is even higher than in the ASIA region. The primary energy use of $47 \mathrm{EJ}$ in the base year increase to a level of $802 \mathrm{EJ}$ in $2100.72 \%$ of this level comes from non-fossil fuels. The emission path in this region is in line with the trends described above. The standardized 
emissions grow from $0.72 \mathrm{GtC}$ in 1990 to $5.72 \mathrm{GtC}$ in 2050 . After this peak they decline to a level of $4.81 \mathrm{GtC}$ in 2100.

In A2 technological development progresses relatively slowly and fossil fuels maintain their dominant position to supply the strongly expanding number of people in the A2-Marker, implemented in the ASF modeling framework. In the longer run, when oil and gas resources become scarcer, coal regains the leading role. By 2100 the contribution of coal in total primary energy use in the OECD, REF, ASIA, and ALM regions amount to respectively $52 \%, 38 \%, 61 \%$, and $48 \%$. In all other scenarios these figures are lower. The low technological improvements in A2 result in the lowest contribution of nonfossil fuels compared to the other scenarios. Global carbon dioxide emissions in A2ASF grow fourfold from 1990 to 2100 with a progressively increasing share of emissions coming from the energy and industrial sources. Hence the growth in energy and industrial emissions is even stronger and they end up at $29 \mathrm{GtC}$, more than 4.5 times over their 1990 level. $\mathrm{CO}_{2}$ emissions grow in all four regions (with exception of REF from 1990 to 2020). Fastest growth occurs in the ASIA and ALM regions as a result of the assumed population projections. Therefore the relative contribution of $\mathrm{CO}_{2}$ emissions from these two DEV regions increases (ASIA from 22 to $37 \%$ of the global total, and ALM from 23 to $31 \%$ ).

The strong trend toward ecologically more compatible consumption and production patterns in B1 is reflected by structural changes towards less energy and materialintensive activities, leading to a de-coupling of welfare and energy demands in the B1Marker. Rapid technological change towards resource saving and ecologically sound solutions is assumed and deployment spreads quickly, facilitated by high capital stock turnover rates in currently less developed regions. As a result energy requirements show a relatively limited growth in the B1-Marker quantified with the IMAGE model. At the same time a shift away from fossil fuels eventually breaks the already slow upward trend in carbon emissions. The peak is around 2040 at $12 \mathrm{GtC}$, twice the 1990 level, and by 2100 the emissions of $5 \mathrm{GtC}$ even fall below the base year level. It is worth noting that, as for A1, the population projection adopted for this scenario family declines after 2050.

In the B1-Marker scenario the OECD region shows a slightly different development compared to the other regions. While both population and energy use grow until 2050 in REF (except for the period until 2020), ASIA and ALM, the downward trend starts in the OECD starts already in 2020. The OECD and REF regions the energy use in 2100 is below base year levels (see also Table 2).

In the B2 world, dynamics of technological change continue along historical trends ("dynamics as usual"). Exploiting the comparative advantages, different from region to region, at the global level a mix of clean fossil and non-fossil supply results. With the continued growth of population and of income per capita, a steady increase of $\mathrm{CO}_{2}$ emissions emerges in the B2-Marker, developed by the IIASA models SG and MESSAGE (for details, see Riahi and Roehrl article in this special issue). By 2050 they are $11.2 \mathrm{GtC}$ (just below the B1-Marker) and by 2100 the level approaches $14 \mathrm{GtC}$, just exceeding the A1B-Marker level. The emission level of the IND region is more or less stable over the time period. The relative share decreases from $69 \%$ in the base year to $31 \%$ in 2100 given the rising emission in the two DEV regions.

In the B2-Marker scenario the fossil fuel and industrial $\mathrm{CO}_{2}$ emission path in the OECD region shows an upward trend until 2020. Afterwards standardized emission decline to $3.3 \mathrm{GtC}$ in 2050 and $3.1 \mathrm{GtC}$ in 2100 . In the later period the use of fossil fuels slightly declines and shifts from oil to gas due to the considerable pressure on the 
oil resource base after 2050. Total energy use increases during the whole next century. In $\mathrm{B} 2$ the standardized fossil $\mathrm{CO}_{2}$ emissions decline to $0.8 \mathrm{GtC}$ in 2020 and show an upward trend to 1990 levels by the year $2100(1.2 \mathrm{GtC})$. During the last phase of the next century the primary energy use decreases while emissions increase. This trend is mainly caused by a fuel switch from gas to coal which is mainly used in the synthetic form as a liquid substitute for oil. In ASIA both primary energy use and carbon emissions increase during the next century. Although the non-fossil fuels gain importance, the contribution of the fossil fuels remains high. The use of coal, oil, and gas increases until 2050. Afterwards the use of oil and gas decrease while the use of coal grows rapidly. In $\mathrm{B} 2$ the population, energy use and emission of the ALM region constantly increase during the next century. Again, the fossil fuels remain playing a dominant role (see Table 2). Gas use increases until 2100. The use of coal is rather stable until 2050 and shows a rapid increase afterwards while the use of oil drops sharply after 2050.

2.2.1.2. OTHER $\mathrm{CO}_{2}$ EMISSIONS. Whereas emissions from the burning of fossil fuels and from industrial processes are expected to unfold along relatively smooth trajectories, other $\mathrm{CO}_{2}$ emissions could well follow much more dynamic pathways in the future. Changes in land-use, the main driving force behind other $\mathrm{CO}_{2}$ emissions, are influenced by the demand for cropland and grassland (to supply vegetable and animal food to the world population) and the role of biomass energy. Already the 1990 emission level is fairly uncertain, estimated at $1.6 \pm 1.0 \mathrm{GtC}[9]$ and the same goes for recent trends. The uncertainty is also reflected in the models used to quantify the scenarios: in 1990 they range between 1.0 and $1.6 \mathrm{GtC}$ and the spread at the four-region level breakdown is even larger. It must be noted that not all models treat land-use change related emissions in the same way: in some cases it concerns only deforestation of tropical forests, while in other cases many more sources and sinks and their net effect are accounted for. For example, the ASF model only includes emissions from deforestation in the ASIA and ALM regions in the land use category. In the A2-Marker decreasing emissions from land use are explained by a reduction of the area, which can be deforested. Therefore a straight comparison between the model numbers cannot be made. For the sake of comparability common, standardized emissions are established at $1.1 \mathrm{GtC}$ in 1990 and $1.0 \mathrm{GtC}$ in 2000 , reflecting the net carbon release resulting from contemporary decline of tropical rainforest. As stated above, the future trajectory of (net) deforestation-related $\mathrm{CO}_{2}$ emissions is very different for the four scenarios, as assumptions on the drivers indicate. In general emissions are expected to drop from their currently high levels. Land-use emissions in the A1B-AIM Marker gradually decline to less than $40 \%$ of the current level by 2050 , but remain around that level afterwards. In the B2MESSAGE Marker, the net emissions drop below zero from 2030 onwards. so on aggregate forests become a sink of carbon in this scenario.

The trend in the A2-Marker has a similar shape, but emissions run at a higher level and remain above zero. In B1, however, the initial decline is followed by a period of renewed growth in the second half of the next century and by 2100 the net emissions are back to $80 \%$ of their current level.

In all four Marker scenarios, both the absolute levels and relative contribution of land-use change related emissions in the DEV region exceed the IND levels. In the IND region the land-use change emissions vary from -0.23 to $0.4 \mathrm{GtC}$. This corresponds to $-5.8 \%$ to $20.9 \%$ of total $\mathrm{CO}_{2}$ emissions in the region. For the $\mathrm{DEV}$ region the emissions from land-use change vary from -0.26 to $1.1 \mathrm{GtC}$. The relative shares are $-2.8 \%$ to $37 \%$ of the total $\mathrm{CO}_{2}$ emissions in this region. 
TABLE 3

$\mathrm{CO}_{2}$ Emission Trends (G1C and Percent)

\begin{tabular}{|c|c|c|c|}
\hline & $\begin{array}{l}\text { World emissions } \\
(\mathrm{GtC})\end{array}$ & $\begin{array}{l}\text { IND } \\
(\%) \\
\end{array}$ & $\begin{array}{c}\text { DEV } \\
(\%) \\
\end{array}$ \\
\hline \multicolumn{4}{|l|}{1990} \\
\hline Fossil fucl and inclustry & $6 .()$ & 69) & 31 \\
\hline Total & 7.1 & 58 & 42 \\
\hline \multicolumn{4}{|l|}{ 2020 } \\
\hline Fossil fuel and industry & $9.0-12.1$ & $38-50$ & $50-62$ \\
\hline Total & $9.0-12.6$ & $37-47$ & $53-6.3$ \\
\hline \multicolumn{4}{|l|}{2050} \\
\hline Fossil fuel and industry & $11.2-16.2$ & $28-40$ & $60-72$ \\
\hline Total & $11.0-17.1$ & $27-40$ & $60-73$ \\
\hline \multicolumn{4}{|l|}{2100} \\
\hline Fossil fuel and industry & $4.9-28.6$ & $23-32$ & $68-77$ \\
\hline Total & $5.7-28.8$ & $22-34$ & $66-78$ \\
\hline
\end{tabular}

2.2.1.3. REGIONAL TRENDS IN TOTAL CO_ EMISSIONS. Table 3 gives an overview of the world $\mathrm{CO}_{2}$ emissions and the relative shares of the IND and DEV regions. The table shows the shift in relative contribution in both fossil fuel and industry-related and total $\mathrm{CO}_{2}$ emissions (including land-use change) from the IND to DEV region. This shift applies to all four Marker scenarios. In general the relative contribution of the IND region is the lowest in $\mathrm{A} 1$ and the highest in $\mathrm{B} 2$.

The shifts in shares in Table 3 are of course the result of different developments in the regional emission trajectories. To illustrate this, the trajectories normalized to the base year $(1990=100$ for each region $)$ are displayed in Fig. 2 .

Besides the obvious conclusion that emissions in the ASIA and ALM regions grow much stronger than in the IND regions, and with one exception also than in the world, Fig. 2 also illustrates that the global trend is strongly shaped by the DEV trajectories. Furthermore, in line with different development perspectives for the four Marker families, $\mathrm{CO}_{2}$ emission levels show the largest differences for ASIA and ALM. In A1 emissions for ALM and ASIA grow roughly in parallel over the entire time horizon (see Fig. 2). In B1 this is only the case in the earlier years; as the peak and the subsequent decline in ALM occur later than in ASIA, they diverge strongly in the second half of the next century. In A2 emissions in ALM start to grow at a lower rate than in ASIA, but then catch up and later the two are again fairly close. In B2, finally, ALM emissions initially grow at a modest rate, close to the OECD90 region and the world trend. In later years the growth in ALM exceeds the global rate, but the total carbon emissions remain far below those in the ASIA region.

\subsubsection{Methane}

Anthropogenic methane $\left(\mathrm{CH}_{4}\right)$ emissions in the year 1990 are estimated at $375 \pm$ $75 \mathrm{Mt} \mathrm{CH}_{4}$ in the previous IPCC assessment. The methane emissions arise from a variety of activities, dominated by biological processes, each associated with considerable uncertainty. After standardization the common level in the four scenario families is around $310 \mathrm{Mt}$ which is within the range mentioned above. About one quarter of the total is related to fossil-fuel extraction (methane emissions from coal mines, methane venting from oil extraction), transport and distribution (leakage from pipelines), and consumption (incomplete combustion). The biogenic sources are related to agriculture (enteric fermentation, rice paddies, and animal waste), to biomass burning and to waste 


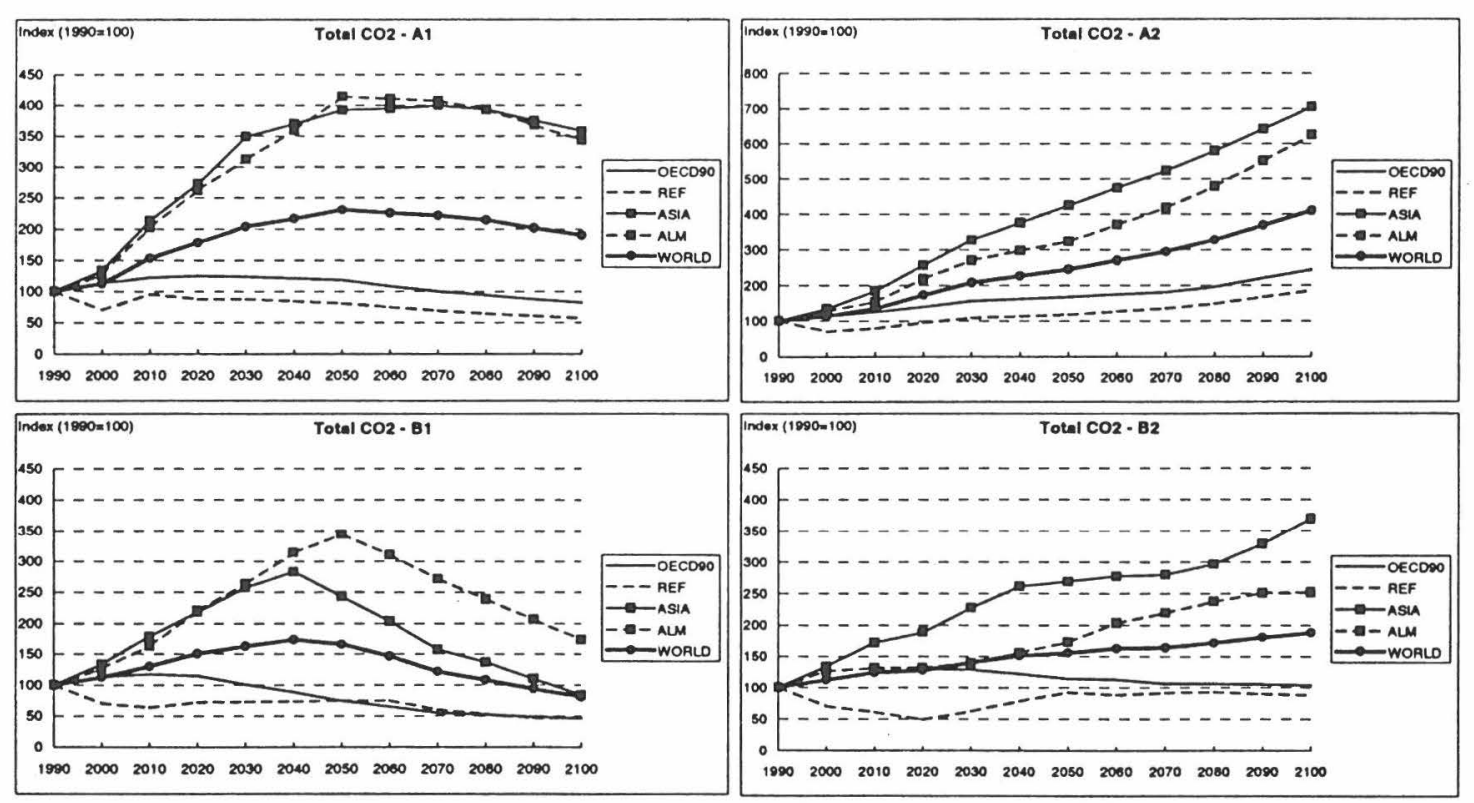

Fig. 2. Total $\mathrm{CO}_{2}$ emissions per region $(1990=100)$. 
from human settlements (landfills, sewage). Hence the future trajectories depend in part on the volumes of fossil fuels used in the scenarios, adjusted for assumed changes in operational practices, but more strongly on scenario-specific, regional demographic and affluence developments, together with assumptions on preferred diets and agricultural practices. Following from the discussion in literature on the observed downward trend in methane concentrations in recent years [10-13] emission factors linking emissions to changes in their drivers is subject to change over time.

The resulting methane emission trajectories for the four Markers are displayed in Fig. 3. For both the A1 and B1-Marker, the emissions level off and then decline sooner or later in the next century. This phenomenon is most pronounced in the A1-Marker, where the fastest growth in the first few decades is followed by the steepest decline and the 2100 level ends up slightly below the current emission of $310 \mathrm{Mt}$. The emission levels in the A2 and B2 scenarios increase in the next century mainly due to the increased population levels and related agricultural practices. Clearly, as actual emissions by source in the base year are fairly uncertain each of the bars shown in Fig. 3 is surrounded by substantial uncertainty ranges.

Opposite to carbon dioxide emissions the relative contribution of the DEV region in total 1990 methane emissions is already larger than the contribution of the IND region. In the base year over $60 \%$ of the total emissions comes from the two DEV regions. In all scenarios this share grows during the next century.

\subsubsection{Nitrous Oxide}

Nitrous oxide $\left(\mathrm{N}_{2} \mathrm{O}\right)$ budgets are subject to considerable uncertainties. [14] gives a range between 3.7 to $7.7 \mathrm{Mt}$ anthropogenic emissions. The largest contribution is from fertilized cultivated soils (1.8 to $5.3 \mathrm{Mt}$ per year), followed by industrial sources with a range between 0.7 to $1.8 \mathrm{Mt}$ [14]. Total natural emissions amounted to $9.0 \pm 3.0 \mathrm{Mt}$ $\mathrm{N}_{2} \mathrm{O}-\mathrm{N}$ in the same year, so oceans, tropical and temperate soils are together the most important source of nitrous oxide today. Atmospheric concentrations of $\mathrm{N}_{2} \mathrm{O}$ in 1992 were 311 ppbv [14] with the 1993 rate of increase being with 0.5 ppbv somewhat lower than in the previous decade of approximately 0.8 ppbv per year [15].

Among the anthropogenic sources, cultivated soils are the largest source, contributing 50 to $70 \%$ of the anthropogenic total. Their emission level are highly uncertain as they are a complex function of soil type, soil humidity, species grown, amount and type of fertilizer applied, etc. The second largest anthropogenic source of $\mathrm{N}_{2} \mathrm{O}$ is industry, where two processes account for the bulk of industrial emissions: nitric acid and adipic acid production. In both cases $\mathrm{N}_{2} \mathrm{O}$ is released with the off-gases from the production facilities.

Standardardized 1990 emissions in the Markers amount to $6.7 \mathrm{Mt} \mathrm{N}_{2} \mathrm{O}-\mathrm{N}$ (see Fig. 4) which is well within the IPCC range. The relative shares of the OECD90, REF, ASIA, and ALM regions in the base year emissions are $39 \%, 9 \%, 34 \%$, and $18 \%$. Even more than for methane, the assumed future food supply will be a key determinant of future nitrous oxide emissions. Size, age structure, and regional spread of the global population will thus be reflected in the emission trajectories, together with assumptions on diets and improvements in agricultural practices. Continued growth of $\mathrm{N}_{2} \mathrm{O}$ emissions emerges only in scenario A2. In the other three Marker scenarios, emissions peak and then decline sooner or later in the course of the next century. The B2-Marker shows the lowest emission level, despite the larger population than in A1 and B1. This is mainly a result of lower emissions from biomass burning and decreasing emissions from fertilized soils due to sustainable agricultural practices. The profile for A1 is the net 


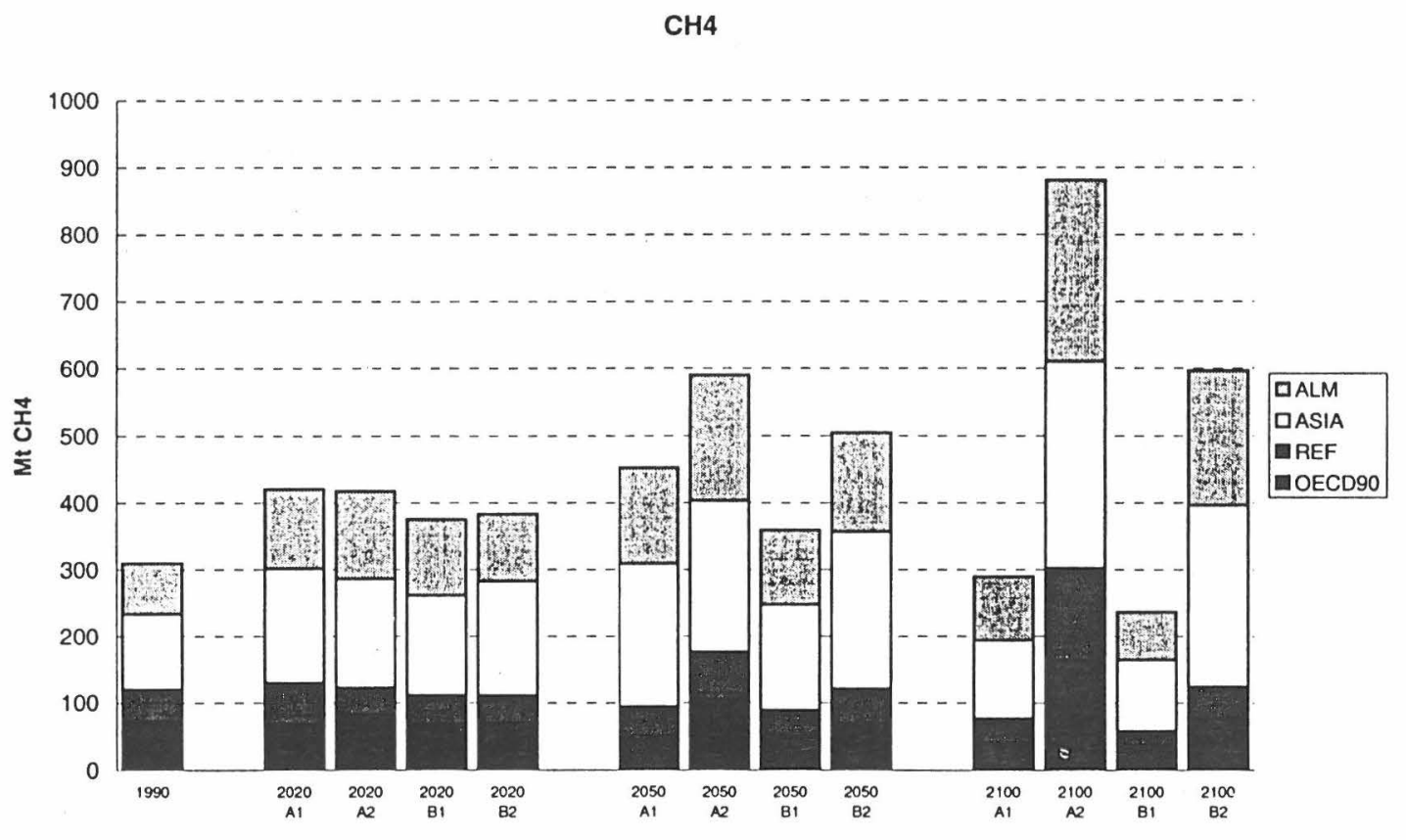

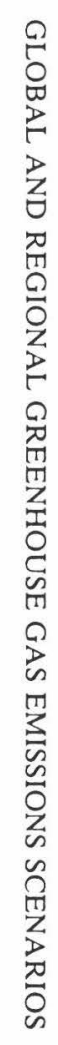

Fig. 3. Methane emissions by region $\left|\mathrm{Mt} \mathrm{CH}_{4}\right|$. 
N2O

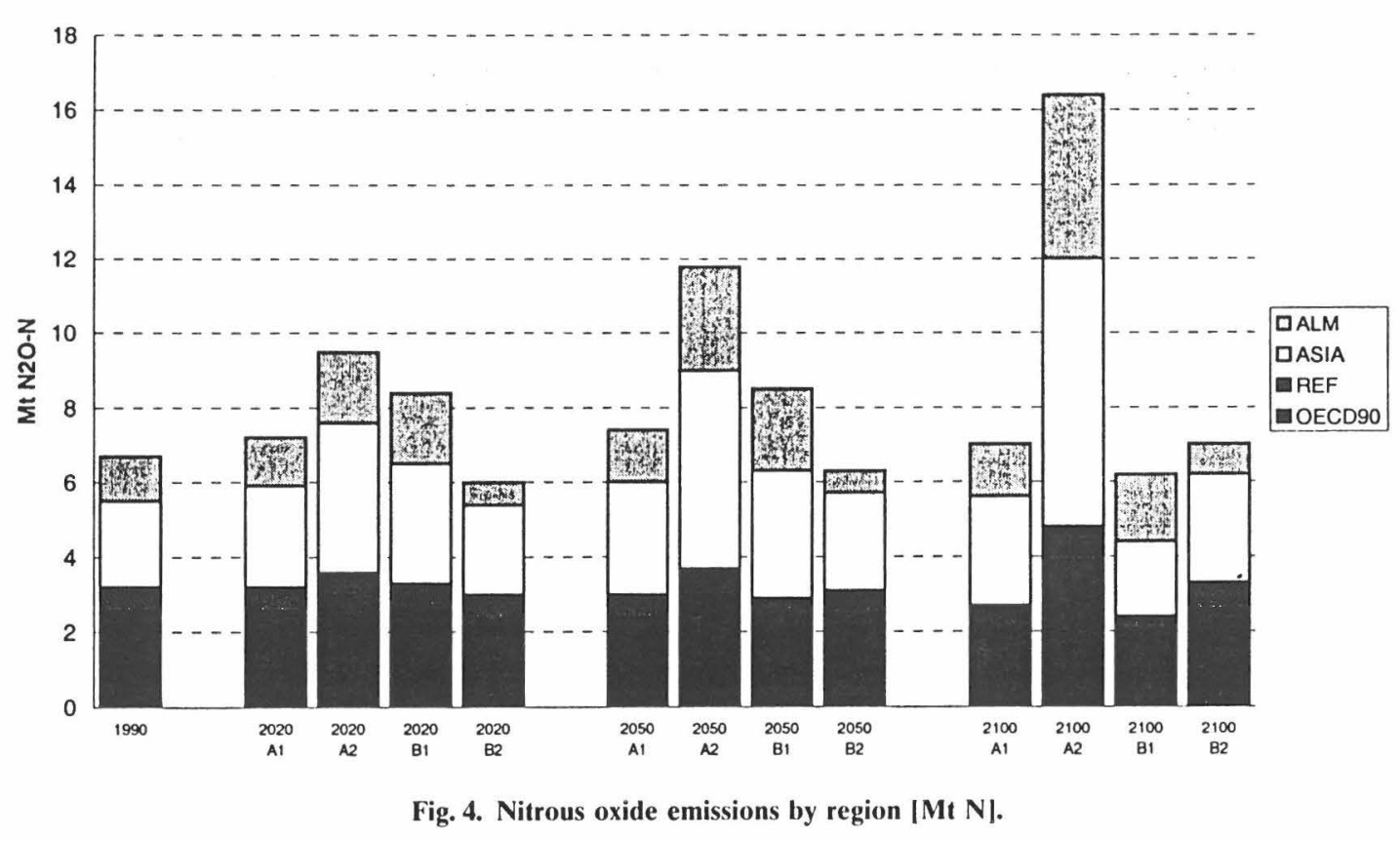


result from relatively quickly declining emissions in the DEV region, due to rapid economic growth and the associated phase-out of traditional agricultural practices, and increasing emissions from industrial processes and transport in all regions. Contrary to what is observed for other emissions, the $\mathrm{N}_{2} \mathrm{O}$ emissions in the B1-Marker take an intermediate course until the middle of the next century before dropping off to the lowest emission level in 2100. It must be noted that, as the largest anthropogenic source of nitrous oxide (cultivated soils) is already very uncertain in the base year, all future trajectories must be treated with great care.

In most scenarios the relative contribution of the DEV region increases. Mainly as a result of the demographic developments the fastest growth occurs in the A2-Marker scenario. In 2100 the share of the DEV region in total nitrous oxide emissions amounts to more than $70 \%$.

\subsubsection{Halocarbons and Other Halogenated Compounds}

The emissions of halocarbons (CFCs, HCFCs, Halons, Methyl-bromide, and HFCs) and other halogenated compounds (PFCs, and $\mathrm{SF}_{6}$ ) were calculated by Fenhann in this special issue on a substance-by-substance basis adopting consistent assumptions with the Marker storylines.

First, for Ozone Depleting Substances (ODS), an external scenario, the new Montreal Protocol scenario (A3) from WMO/UNEP [16], the draft Scientific Assessment of Ozone Depletion, is used. Since most measures reflected in the scenario already have been taken or are well established and under way, no large variation is expected between scenarios. Therefore, the WMO/UNEP A3 scenario on ODS applies to all scenarios. For the other gas species a simple methodology of developing different emission trajectories consistent with aggregate Marker Scenario driving force assumptions (population, GDP, etc.) has been developed. Scenarios are equally further differentiated concerning assumed future control rates for these gases, varied across the scenarios consistent with tee interpretation of the storylines. The literature, as well as the scenario methodology and data are documented in more detail in Fenhann in this special issue.

Halocarbons are carbon compounds containing fluorine, chlorine, bromine, and iodine. Halocarbons that contain chlorine (CFCs and HCFCs) and bromine (halons) cause ozone depletion and their emissions are controlled under the Montreal Protocol and its Adjustments and Amendments. According to the 1987 Montreal Protocol and its subsequent amendments, CFCs were largely banned for developed countries after January 1996 (and developing countries after 2010), although some countries have failed to meet the deadline. Furthermore, HCFC usage will be subject to a gradual phase-out with cuts of $35 \%, 65 \%$, and $90 \%$ in 2004,2010 , and 2015 , respectively. Final HCFC consumption phase-out will occur in 2020 (2040 for developing countries).

HFCs are now beginning to be produced as replacements for CFCs and HCFCs. Unlike the CFCs and the HCFCs, HFCs do not convey chlorine to the stratosphere and thus do not contribute to ozone depletion.

In the development of the future HFC emissions, Fenhann in this special issue a procedure based on the work by Kroeze [17] that is based on the following two steps:

1. "Virtual" future CFC emissions are first calculated assuming a situation without the Montreal Protocol.

2. CFCs are substituted with HFCs according to substitution percentages adopted from the literature and reflecting also varying degrees of emission reduction potentials due to better housekeeping measures and due to technological changes. 
Concerning Step 1 of the methodology used in Fenhann in this special issue, 1990 CFC emissions were taken from the forthcoming Scientific Assessment of the Ozone Depletion [16]. Pre-Montreal 1986 emissions were taken from Hammitt et al. [18] for most of the species. For some of the species 1990 emissions were scaled back to PreMontreal conditions in 1986. proportional to the development in the sales from 1986 to 1990 using the sales figures in the AFEAS report [19].

Future "potential" (assuming no Montreal protocol) emissions of CFCs were projected proportional to the development of GDP consistent with the four Marker scenarios and assuming in addition a saturation of per capita demands, varied according to the four different Scenarios storylines. This projection of the CFC emissions trajectory in the absence of the Montreal Protocol reflects how the demand for services using these substances could develop in the future. With the Montreal Protocol in place different chemical compounds will be used to replace the Montreal gases. In order to compute the amount of CFC replaced with these other compounds, future CFC emissions with the Montreal Protocol in place were first subtracted from the "potential" CFC emissions using the above mentioned WMO/UNEP A3 ODS scenario [16].

To avoid HFC emissions by using non-halocarbon substitutes, better housekeeping can also help reduce emissions. For instance, spilling of cooling agent while filling the equipment could be reduced. Second, releases can be reduced during use by leakage control. And finally, halocarbons can be recovered for reuse or destruction when equipment is discarded. Even in non-intervention scenarios as reported here, some of the reduction potential is likely to be realized as a result of technological changes introduced to reduce ozone-depleting substances. Reduction rate percentages were varied over time and between industrialized and developing countries reflecting the different scenario storylines. Generally, reduction rates are assumed highest in scenarios with an emphasis on environmental policy (B1). For one scenario (A2) no reductions were assumed whereas in the other scenarios intermediary reduction rates and levels were assumed.

PFCs are fully fluorinated hydrocarbons. Because of their extreme long atmospheric lifetimes (2,600-50,000 years), they have particularly high radiative forcing. The Production of aluminum $(\mathrm{Al})$ is thought to be the largest source of emissions of the PCFs $\mathrm{CF}_{4}$ and $\mathrm{C}_{2} \mathrm{~F}_{6}$. The scenarios developed by Fenhann in this special issue adopted a methodology of projecting future aluminum demand based on (1) aluminum consumption elasticities with respect to GDP, (2) use of alternative assumptions concerning recycling rates, and (3) varying emission factors reflecting future technologies change. These assumptions are varied in consistency with the four scenario storylines.

PFCs are also consumed in small amounts in other uses such as in electronics, as tracers and in cosmetics and medical applications. However, the only emissions included in Fenhann in this special issue beyond Al-production, were PFCs $\left(\mathrm{C}_{4} \mathrm{~F}_{10}\right.$ and higher $)$, which replace CFCs as described above.

Sulphurhexafluoride $\left(\mathrm{SF}_{6}\right)$ is an extremely stable atmospheric trace gas. Its unique physico-chemical properties make this gas ideally suited for many specialized industrial applications. The remaining about $20 \%$ of the present global $\mathrm{SF}_{6}$ emissions $(1,200$ tons per year) are presently emitted from magnesium foundries, where $\mathrm{SF}_{6}$ is used to prevent oxidation of molten magnesium. $\mathrm{SF}_{6}$ is also used to degas aluminum, but $\mathrm{SF}_{6}$ reacts with aluminum, thus little or no net $\mathrm{SF}_{6}$ gas is released to the atmosphere in this process. The global production of magnesium is about 350,000 tons [20]. At present developing countries account for about $15 \%$ of world magnesium production. It is assumed that the rest of the $\mathrm{SF}_{6}$ emissions $\left(80 \%\right.$, or 4,600 tons $\mathrm{SF}_{6}$ per year at present) originates from the use of $\mathrm{SF}_{6}$ as a gas insulator in high voltage electricity equipment. The unique 
ability of $\mathrm{SF}_{6}$ to quench electric arcs, has enabled the development of safe, reliable gasinsulated high-voltage breakers, substations, transformers, and transmission lines. The demand for such electrical equipment is assumed to grow proportional to the electricity demand [21]. With an emission factor of 132.6 ton $\mathrm{SF}_{6} / \mathrm{EJ}$, Fenhann in this special issue, uses preliminary electricity generation projections from the four Marker scenarios and assumed additional varying potentials for emission reductions resulting from more careful handling, recovery, recycling and substitution of $\mathrm{SF}_{6}$. Reduction rates are again varied according to the scenario storylines. The detailed assumptions are reported in Fenhann's article in this special issue.

The effect of climate of each the substances varies greatly due both to differences in atmospheric lifetime and differences in the radiative effect per molecule of each gas. The net effect on climate of these substances is best determined by a calculation of their radiative forcing-which is the amount by which these gases enhance the anthropogenic greenhouse effect. The net radiative effect of halocarbons, PFCs and $\mathrm{SF}_{6}$ from 1990 to 2100 , including a current estimate of the radiative effect of stratospheric ozone depletion and subsequent recovery, ranges from $6-9 \%$ of total radiative forcing from all greenhouse gases and sulfur dioxide. This is comparable to the present effect of these gases on climate. Anticipating more detailed assessment of the radiative forcing, here the less accurate concept of Global Warming Potentials (GWP) (see subsection 2.2.6.) is applied to estimate the aggregate effect of the many different halogenated substances.

Fig. 5 presents the emission trajectories of halocarbons and other halogenated compounds. It must be noted that the Montreal gases are not included in the figure as only world totals are available. In the reference year the emissions are mainly emitted by the OECD90. The share of the DEV region is relatively small. During the next century this share increases. The figure also shows that the total emissions increase in all regions compared to the reference year.

\subsubsection{Distribution of Total Greenhouse Gas Emissions over Individual Gases and Regions}

This section discusses the distribution of all greenhouse gases. The aggregation of the gases is based on the concept of the Global Warming Potential. ${ }^{3}$ Fig. 6 presents the aggregated greenhouse gas emissions for the four Marker scenarios.

In the A1 Marker greenhouse gas emissions grow rapidly in all regions until the middle of the next century. In particular $\mathrm{CO}_{2}$ emissions from fossil fuel and industrial sources expand as a result of the high economic growth rates assumed in all regions, and the accompanying increased use of fossil fuels despite rapid technological progress. Thereafter new, non-fossil energy supply options start to supply increasingly large shares of the total primary energy requirements and demand for energy services levels off as the population declines. The relatively small population, together with rapid development and spread of advanced practices also imply that the growth of agriculture and land-use related missions is limited.

The ongoing growth of the population, concentrated in the DEV regions, and the relatively slow technological progress assumed in the A2 Marker lead to high emission

\footnotetext{
${ }^{3}$ The Global Warming Potential (GWP) attempts to provide a simple measure of the relative radiative effects of emissions of various GHGs. It gives an index (normalized to $\mathrm{CO}_{2}$ ) defined as the cumulative radiative forcing between the moment of emission of one mass-unit of greenhouse gas and a chosen time horizon. Although GWPs are commonly quoted as single values, typical uncertainty is $\pm 35 \%$, inter alia as they depend upon the-uncertain - fate of the gas emitted and must include direct and indirect effects. Here the IPCC estimates for a time horizon of 100 years are adopted [15].
} 


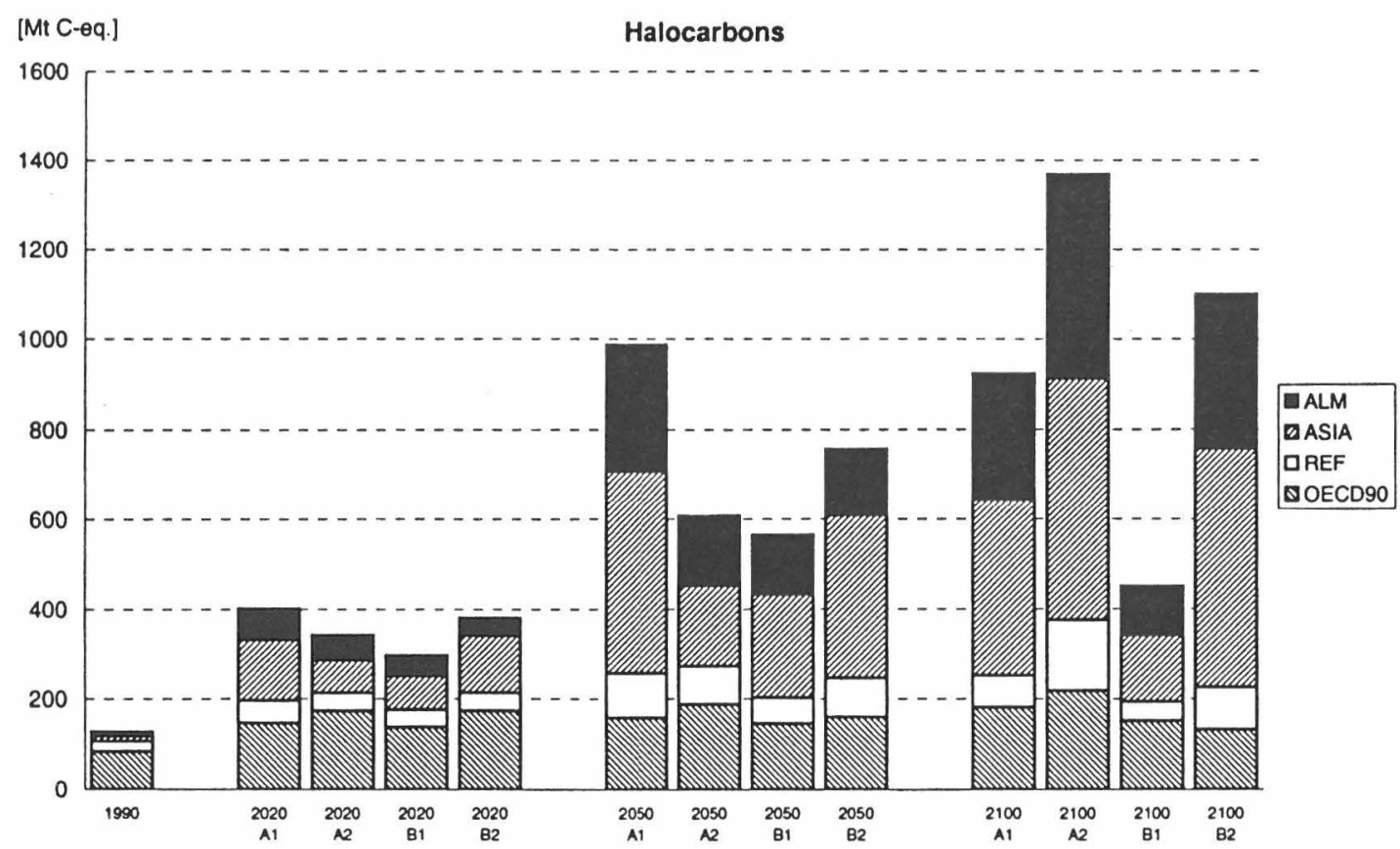

Fig. 5. Halocarbons and other halogenated compounds emissions (excluding Montreal gases) [Mt C-equivalent]. 


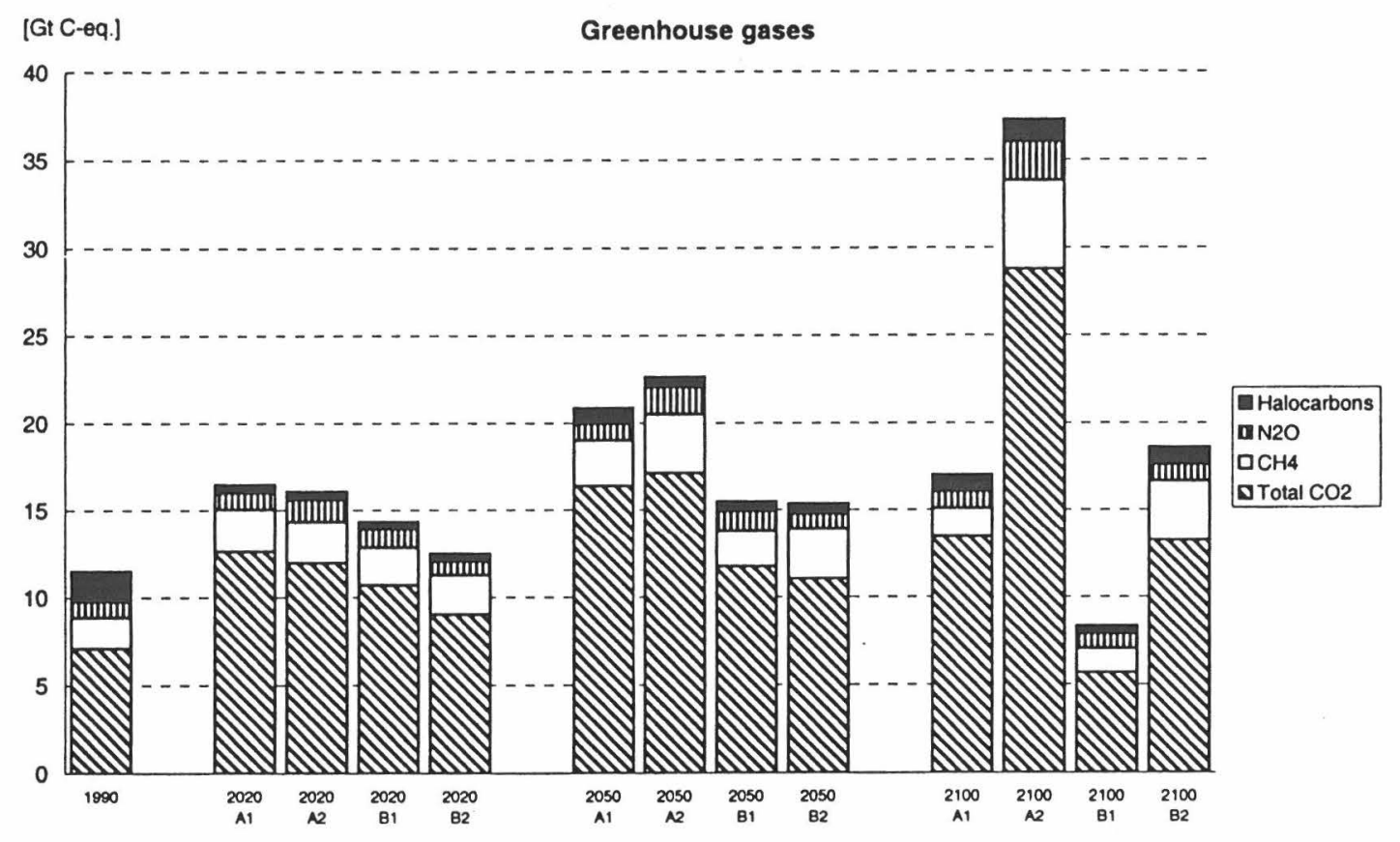

Fig. 6. Greenhouse gas emission trajectories [GtC-equivalent]. 
growth rates. $\mathrm{CO}_{2}$ and methane from fossil fuels keep increasing with the continued reliance of these energy resources to meet the growing demands. At the same time, to feed the growing number of people requires a growing agriculture with associated emissions of $\mathrm{CH}_{4}$ and $\mathrm{N}_{2} \mathrm{O}$. Hence the emissions of all three gases keep growing, and in addition the use of HFCs and other halogenated gases grows considerably, by 2100 approaching the 1990 level of CFCs and HCFCs.

As B1 shares its population projection with $\mathrm{A1}$, emissions of $\mathrm{CH}_{4}$ and $\mathrm{N}_{2} \mathrm{O}$ which are dominated by agricultural activities do not differ much. Economic growth, however, is lower in B1 and is geared towards more sustainable development including dematerialization. Hence energy consumption is much lower than in $\mathrm{A} 1$, and so is the future level of carbon emission.

In the B2 Marker emissions of all GHGs continue to grow, albeit at a lower pace than in A2. On the one hand this can be attributed to the lower population projection adopted, on the other hand to concerns over local environmental problems that foster deployment of cleaner and more efficient technologies and utilization of non-fossil energy resources.

Fig. 7 shows two sets of distribution charts of total global GHG emissions. The panels on left depict the distribution over the regions while the panels on right shows the shares of the individual greenhouse gases.

The left-hand panels of Fig. 7 confirm the shift from the OECD90 and REF regions to the ASIA and ALM regions. While in 1990 the two IND regions together emitted more than $50 \%$, by 2100 their share ranges from one quarter to one third in the four Marker scenarios. Stronger growth in population and in GNP in the DEV regions is thus, unsurprisingly, translated into a bigger share of global GHG emissions. It is worth noting that by 2100 the share of the DEV regions in GHG emissions (66\% to $78 \%$ ) is much more in line with their share of the global income $(58 \%$ to $71 \%$ ) on a market exchange rates (MER) basis than was the case in 1990: $46 \%$ of global emissions but only $16 \%$ of GNP.

In contrast with the regional breakdown, the contribution of the various GHGs does not change drastically over time. Differences are also relatively limited between the four Markers in the year 2100; see the rightmost part of Fig. 7. The most striking trend concerns the growing relative contribution of carbon dioxide in all scenarios. By $2100 \mathrm{CO}_{2}$ contributes to about $70 \%$ to $80 \%$ of total greenhouse gas emissions.

\subsection{SULFUR}

Global anthropogenic sulfur emissions are estimated to range between 65 to 90 $\mathrm{MtS}$ in 1990 [14, 22-24]. A review of most recent inventories given by Smith et al. [25] and Grübler [26], indicates a most likely value of $75 \pm 10 \mathrm{MtS}$ drawing on a large body of literature sources and sulfur inventories (in particular the EMEP and CORINAIR inventories for Europe, NAPAP for North America, and the most recent inventories available for Asia, including [27-29]). Anthropogenic emissions compare to natural sulfur flows estimated to range between 4 to $45 \mathrm{MtS}$ [14]. Pepper et al. adopted an intermediary constant natural sulfur flux of $22 \mathrm{MtS}$ for the IS 92 scenario series [30].

Even with a comparatively good agreement on global sulfur emission levels, important uncertainties remain at the sectorial and regional level. These are discussed in more detail by Alcamo et al. [1] and Grübler [26]. Main sources of uncertainties are a lack of detailed inventory data (especially for developing countries outside Asia, but also for the non-European part of Russia), uncertainties in sulfur contents of fuels (especially coal) in many regions, as well as the use of different base years for develop- 

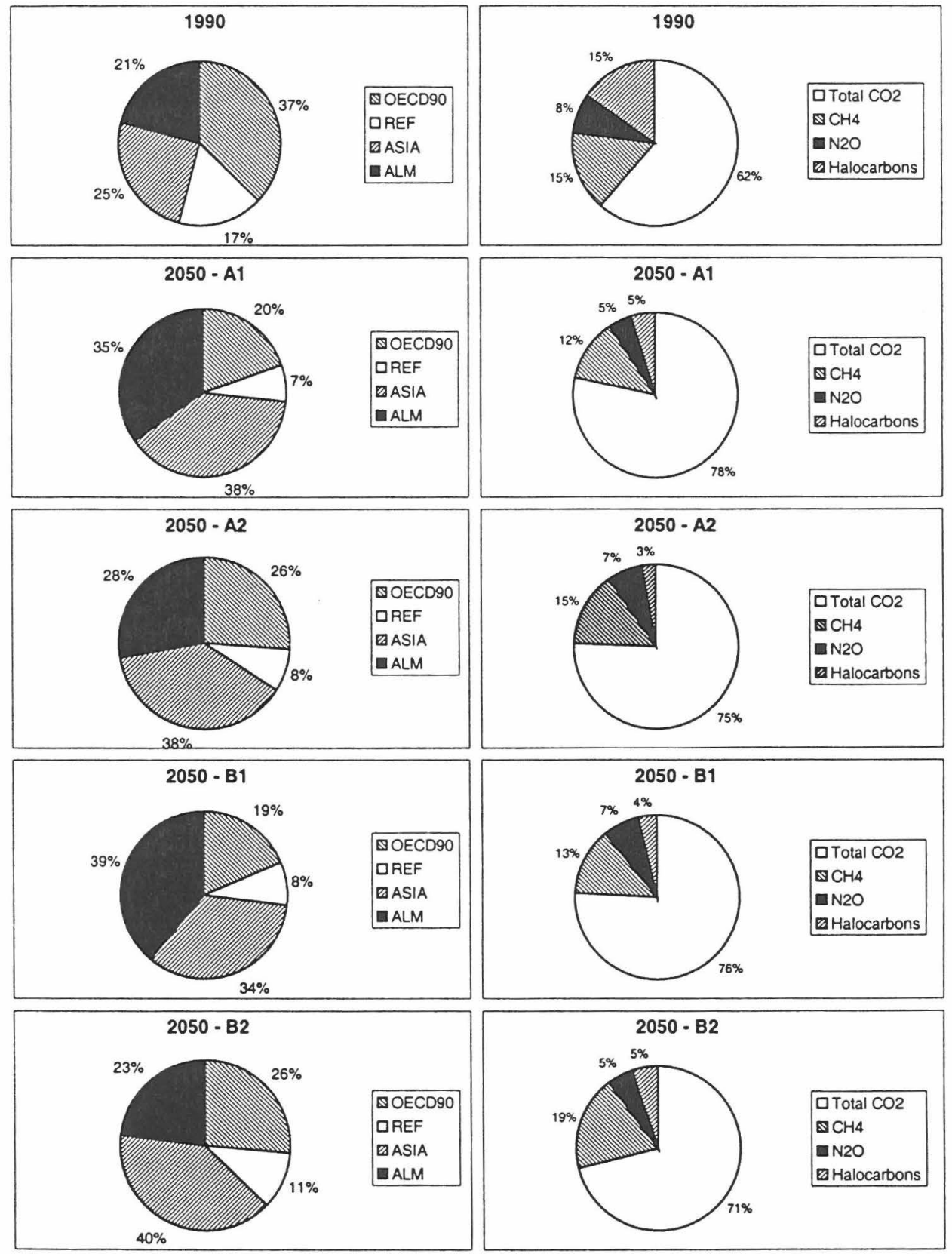

Fig. 7. Distribution of GHG emissions per region (left) and distribution of gases (right).

ment of sulfur inventories. For instance inventories and scenario studies for China and Centrally Planned Asia give a range of sulfur emissions differing by more than a factor of two (8.4 to $18 \mathrm{MtS}$ ) for the year 1990 [26].

Base year differences in available inventory data are especially important because regional sulfur emissions trends have changed drastically in the last decade declining strongly as a result of sulfur control policies in Europe and North America, and increasing 

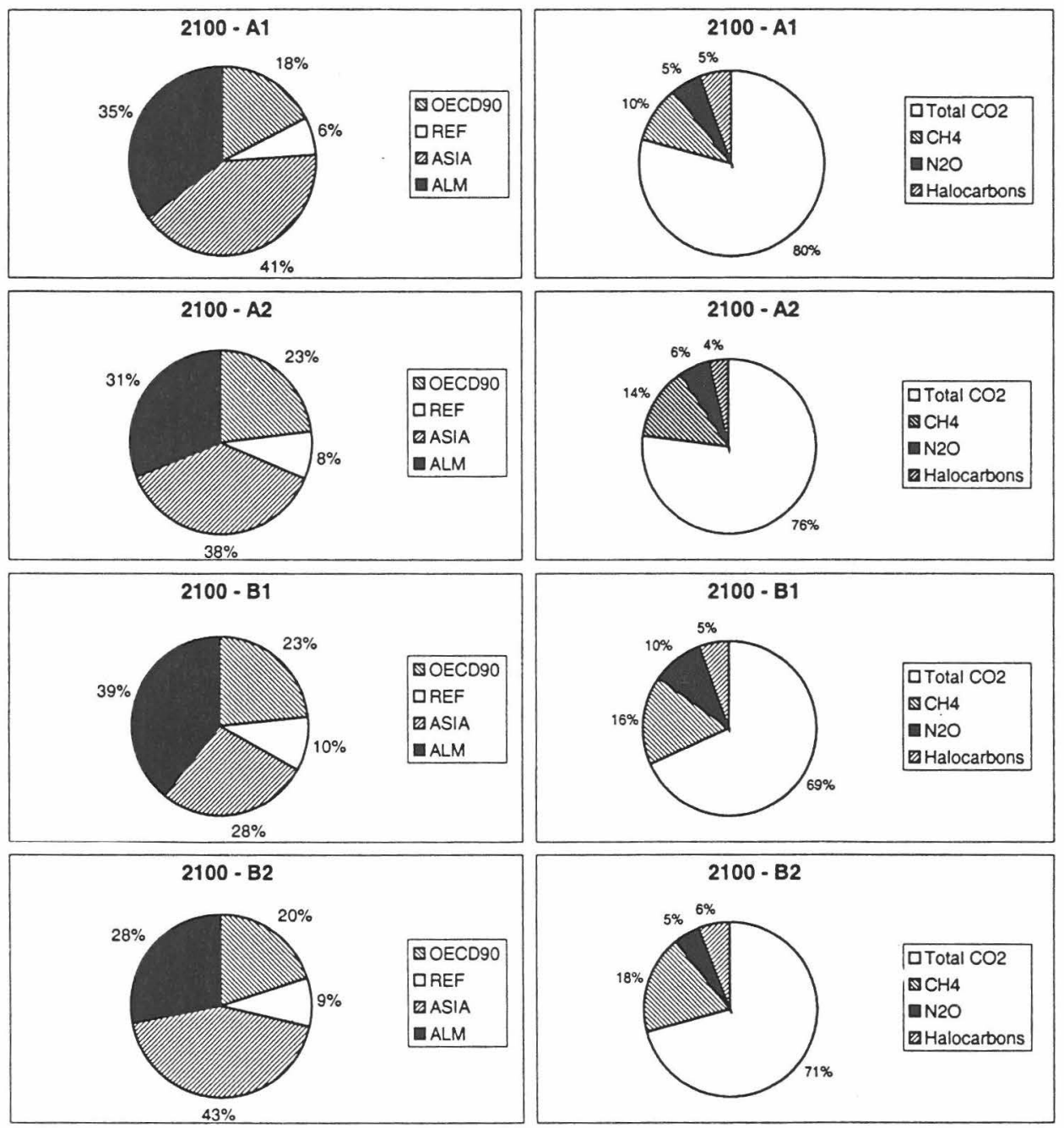

Fig. 7. (cont'd)

rapidly in Asia with growing energy demand and coal use. For instance, between 1980 and 1995, sulfur emissions declined by $59 \%$ in Western Europe and Russia (albeit for entirely different reasons: environmental policy in Western Europe versus a massive economic depression in Russia), by $37 \%$ in Eastern Europe, and by $36 \%$ in North America [31]. Conversely emissions in China have risen rapidly, from an estimated 6.6 MtS in 1985 to $9.1 \mathrm{MtS}$ in 1994 , or by $38 \%$ [32,33]. These diverging emission trends and their rapid changes requires also a continuous updating of available gridded sulfur emission inventories $[22,23,34,35]$, that in some instances still relies on outdated 1980 emission data.

This recent break in emission trends is not reflected in older emission projections, in particular the previous IS92 scenario series. The IS 92 scenario evaluation [1] concluded that the IS92 scenario series only to a limited degree reflect recent legislation to reduce sulfur emissions (e.g., the amendments to the Clean Air Act in the USA or the Second 
European Sulfur Protocol). Hence. particularly regional sulfur emissions in OECD countries projected in IS 92 are much higher than more recent scenarios taking account these legislative changes (see also the discussion in Houghton et al. [14]. pp. 155-156). A detailed review of regional sulfur emission projections is given by Grübler [26].

The conclusion is that the previous IS92 sulfur emission scenarios are outdated and need to be replaced by new sulfur emission scenarios consistent with recent OECD trends as well as the literature on impacts of high unabated sulfur scenarios on human health, food supply, and ecosystems in developing countries as discussed below.

Emissions of sulfur oxides $\left(\mathrm{SO}_{\mathrm{x}}\right)$ have important local and regional effects on human health, food security, and ecosystems. Sulfate aerosols have also an important influence on the climate system. The main sources of anthropogenic $\mathrm{SO}_{x}$ emissions are energyrelated coal and oil combustion, and to a lesser extent industrial activities, biofuel combustion and international shipping

Model differences at the regional level are even larger, reflecting the greater uncertainty of emission inventories at the regional level, particularly outside the OECD90 countries. For standardization of sulfur emissions, the number of regions was increased to six regions, including Latin America and Centrally Planned Asia and China. Important differences in economic development status and resource endowments lead to different patterns of sulfur emissions across all Marker scenarios. Regional emissions were standardized and then aggregated to global totals. Global standardized base year emissions for 1990 for the Marker scenarios are $70.9 \mathrm{MtS}$, in line with the literature range of global emission inventories given above. The regional sulfur emission profiles were also used to generate spatially gridded emission patterns.

Concerning future emission of sulfur, the Marker scenarios estimate global anthropogenic emissions of between 32 to $139 \mathrm{MtS}$ by 2050 and between 16 and $83 \mathrm{MtS}$ by 2100. Compared to the IS 92 scenarios [1] with emissions of 80 to 200 by 2050 and 60 to 230 by 2100 , future sulfur emissions of the Marker scenarios are significantly lower. Only the two lowest scenarios, IS92c and IS92d, approach the higher and estimates of the scenario range in 2100 . This trend reflects both the impact of recent legislation for a drastic reduction in sulfur emissions in OECD countries as well as an anticipated gradual introduction of sulfur control policies in developing regions in the long term. This reflects the recent findings from studies analyzing high impacts on human health, food production, and ecosystems vitality of continued unabated sulfur emissions. Thus, all Marker scenarios anticipate increasing levels of sulfur control, whose rates and timing however are varied across the scenarios, ranging from rapid introduction of stringent controls in scenario B1 to more gradual, later and less stringent controls in scenario A2. It is important to note that all of the scenarios are sulfur-control scenarios only and do not assume any additional climate-policy measures. There is however a certain indirect GHG-emission-reduction effect from sulfur-control policies leading to energy conservation and interfuel substitution from high sulfur to low sulfur fuels (e.g., from coal to gas).

Common to all scenarios is that with increasing affluence, energy use per capita rises and its structure changes away from direct use of solid fuels such as coal and fuelwood towards higher-quality energy forms. This structural shift combined with greater emphasis on air quality, which is also linked to the income level, results in regions with low income (ASIA, ALM) that increase in sulfur emissions at the beginning of the next century, then pass through a maximum and decline in the long-term. In "high income regions" (OECD90, REF) sulfur emissions have already passed their peaks and are actually declining. Despite this similarity in the overall pattern of long-term 
emissions, future emission trajectories across scenarios differ depending on assumptions concerning timing and extent of sulfur-control measures, income and energy-demand growth and technological progress. Fig. 8 includes anthropogenic sulfur emissions for the four Marker scenarios.

In the A1B-Marker scenario, high economic growth combined with high-demand growth results in global sulfur emissions increasing to a peak of $100 \mathrm{MtS}$ in 2020 . After 2020 sulfur emissions decline steadily to about $25 \mathrm{MtS}$ which corresponds to less than the half of global emissions in 1990 . The relatively rapid desulfurization in A1 compared to the other Scenarios is mainly due to high capital turnover rates and, therefore, rapid diffusion of new and clean technologies (mainly renewables and gas) combined with high income levels already in the middle of the next century in the developing world.

In the A2 scenario, technological progress and income growth is slowest of all other scenarios. As a result, the primary energy mix in 2100 is dominated by fossil fuels, for example about $50 \%$ of the primary energy is supplied by coal in 2100 . Although measures are adopted to limit local and regional environmental damages, sulfur-mitigation measures are less pronounced than in the other scenarios. Therefore, global sulfur emissions are highest in A2. They increase to about $113 \mathrm{MtS}$ by 2030 and decrease later to about $60 \mathrm{MtS}$ in 2100 . Nonetheless, even in this most pessimistic scenario with respect to sulfur emissions, emission trends decline in the post-2030 period and are substantially below earlier scenarios in which no (or ineffective) sulfur controls were assumed (such as IS92a or IS92f).

In the B1 scenario, the emphasis is on global solutions to environmental sustainability and improving welfare and development equity. High technology progress rates for renewable technologies result in a continued structural shift away from fossil fuels. This combined with dematerialization of the economy and with the most pronounced sulfur mitigation measures assumed among the scenarios result in sulfur emissions that peak around 2020 at about $80 \mathrm{MtS}$ and eventually decline to $26 \mathrm{MtS}$ in 2100.

In the B2 scenario, strong emphasis is placed on regional environmental protection. Dynamics of technological change continue along historical trends ("dynamics as usual"), that is slower than in A1 or B1, but faster than in A2. The resulting sulfur emissions are $66 \mathrm{MtS}$ by $2020,56 \mathrm{MtS}$ by 2050 and then decline further to about $48 \mathrm{MtS}$ by 2100 . Sulfur emission projections for the B2-Marker were modeled based on the minimization of exceedance of critical loads of acidic deposition using the methodology described in Ammann et al.'s 1996 report [36].

The sulfur-emissions from the scenarios reflect the range given in recent sulfur-control and acidification-impacts analyses scenarios. Therefore, future emissions are generally lower than in the previous IS92 scenario series that were, except IS92c and IS92d, representative of the range of no-sulfur-control scenarios available in the literature.

The regional distribution of sulfur emissions is also important from the climate point of view. Sulfate aerosols (due to increasing sulfur emissions), have a possible global mean cooling effect [15] and a positive or negative local temperature change. For a quantitative description of these effects in the Marker scenarios see Schlesinger et al. in this special issue. This analysis shows that the rapid decrease of sulfur emissions from its present value in the IND regions result in significant warming in these regions. This shows that mitigation of the acid-rain problem by reducing $\mathrm{SO}_{\mathrm{x}}$ emission exacerbates the greenhouse problem in specific regions. The decrease in ASIA sulfur emissions in scenario $\mathrm{A} 1$ and $\mathrm{B} 1$, and to a lesser extent in $\mathrm{A} 2$ and $\mathrm{B} 2$, lead to a relative local warming in this region as well. 
Sulfur

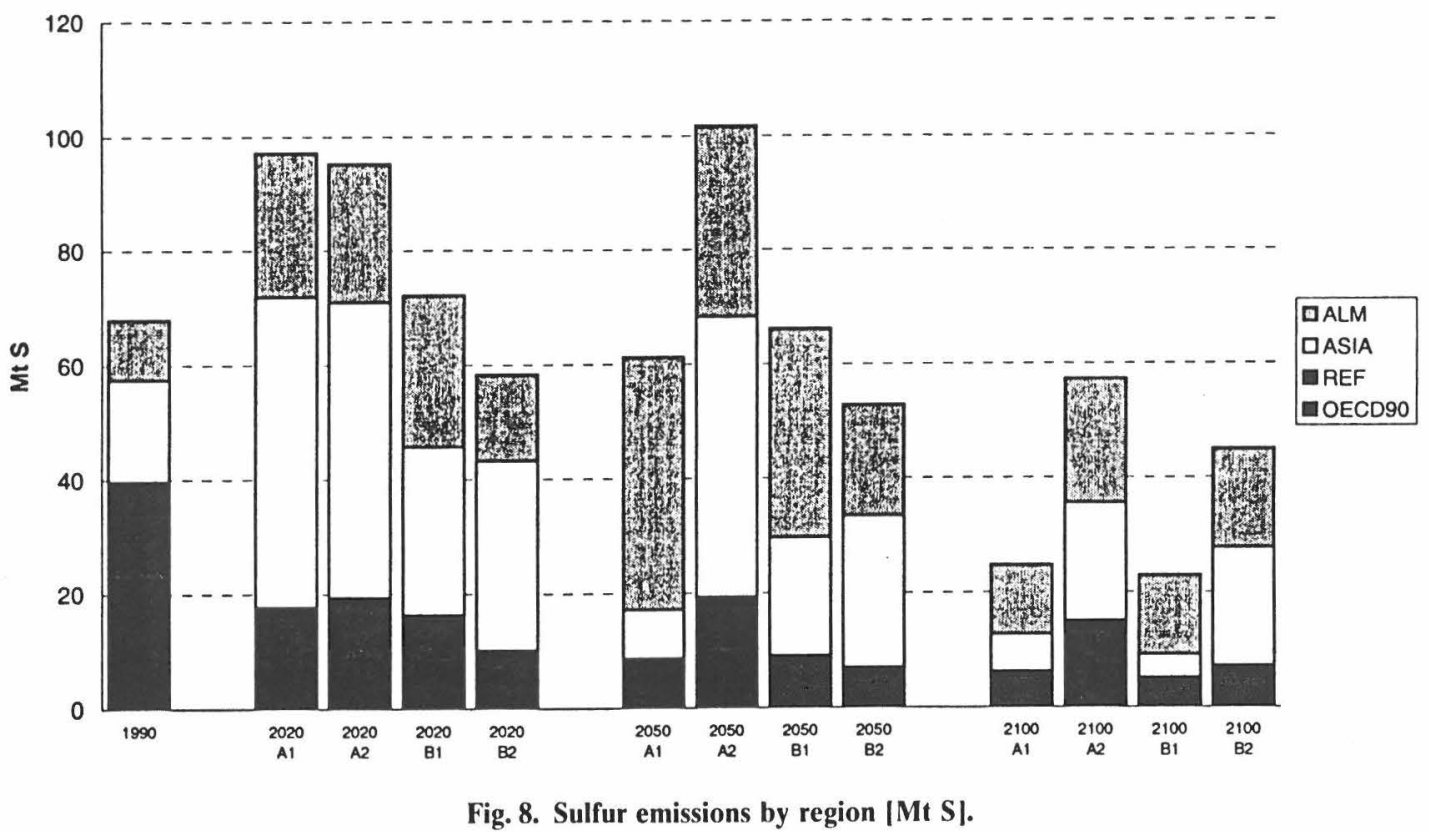

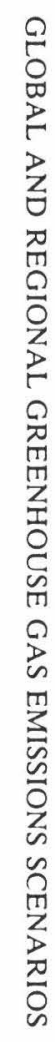

Fig. 8. Sulfur emissions by region [Mt S]. 


\section{Cross-Scenario and Cross-Region Comparison of Indicators}

As shown in the previous sections, greenhouse gas emissions develop along quite different pathways for the four regions and the various substances considered in the four scenario families. While the presentation and discussion thus far focuses on absolute GHG volumes, it is also of interest to examine how the emissions develop relative to other scenario variables like GDP, energy consumption and population. On the one hand cross-scenario comparison of such derived indicators illustrates how trends develop for a certain region under various scenario assumptions. On the other hand, comparing regional trends in indicators illustrates how regions develop within a given scenario family. The discussion below looks at the following five indicators:

- Energy Intensity of GDP (a measure of the efficiency of final energy consumption to generate economic output);

- Carbon Intensity of Primary Energy (a measure of the reliance on fossil energy resources to provide for primary energy requirements);

- Total Carbon Emissions per Capita (a measure of the carbon emitted per capita);

- Methane Emissions per Capita (a measure of the methane emitted per capita);

- Total GHG Emissions per Capita (a measure of the total greenhouse gas release per capita, expressed in carbon-equivalents).

\subsection{ENERGY INTENSITY OF GDP}

In 1990 the amount of final energy consumed per unit of economic output varies strongly between the four regions, indicating big differences in the efficiency that energy is used to generate goods and services. In the REF and ASIA regions, in particular, the intensity is five to seven times higher than in the OECD90 countries. It must be noted that economic outputs are measured here using market exchange rates (MER) to convert currencies to one common denominator. The purchasing power parity (PPP) may be a more relevant indicator for such comparisons. In the REF region and the bigger ASIA countries there is a huge difference between these MER based figures and their PPP equivalents. In contrast to emissions, that were standardized for 1990 and 2000, energy consumption and economic output differ between the models used to explore the four Markers. This is most pronounced for A2, as the final energy reported by the ASF model does not include non-commercial fuels. For the DEV regions these are still important today, and thus the 1990 values for ASIA and ALM look much lower. With time, however, in all models and scenario calculations the role of noncommercial fuels declines strongly as countries become more affluent. Hence, from 2020 onwards trends can be compared better across scenarios and across regions in A2.

In the A1- and B1-Markers there is a global trend towards convergence of energy intensities, as well as a strong overall decline. The high level of global cooperation assumed in these two families forms a favorable condition for development and widespread application of new, more efficient technologies. By 2050 all regions are at or below the current OECD90 level, and continue on a downward slope. Downward slopes are also found in all regions and over the entire time horizon in the other two scenarios A2 and B2. However, there is less convergence and the overall rates of efficiency improvement are smaller than in the two other scenarios. Clearly the lower economic growth assumed in $\mathrm{A} 2$ and $\mathrm{B} 2$ compared with $\mathrm{B} 1$ - and even more with $\mathrm{A} 1$-are important in this respect, as they lead to slower capital stock turnover. (See energy intensity of GDP in Fig. 9.) 

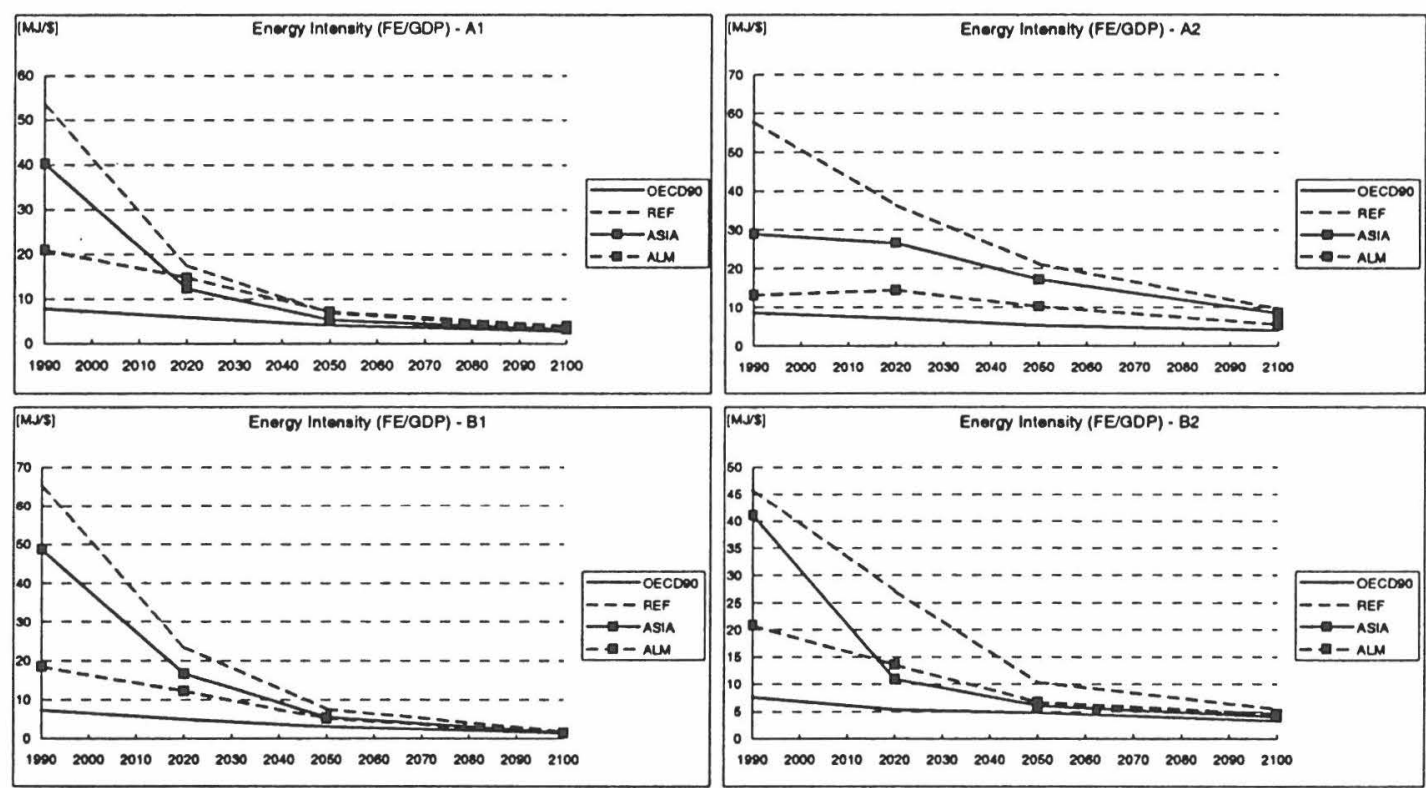

Fig. 9. Energy intensity of GDP. 


\subsection{CARBON INTENSITY OF PRIMARY ENERGY}

While big differences are observed for current energy intensities between regions, the carbon released per unit of primary energy consumed falls in a relatively narrow band. This indicates that at the four region level, the reliance on fossil fuels is not very different although the mix of coal, oil and natural gas is also of influence. In all scenarios but $\mathrm{A} 2$ the carbon intensity drops, albeit for different reasons. In B1 and B2, these include environmental concerns tend to discourage the use of fossil fuels, while in A1 the declining role for fossils is a side-effect of rapid technological progress. The more or less stable carbon intensities in A2 underline the tendency to exploit the cheapest resources available to the regions, favoring fossil fuels abundantly available at moderate prices in this scenario family. (See Fig. 10.)

\subsection{TOTAL CARBON EMISSIONS PER CAPITA}

Fig. 11 presents the total carbon emissions per capita. The reference year shows a big gap in per capita emissions between the IND and DEV regions. In 1990, the emissions per capita in ASIA and ALM are respectively 3 and 6 times below the IND level. The levels converge in the $\mathrm{A} 1$ and to a lesser extent in the $\mathrm{B} 1$ scenario reflecting the convergence in income per capita between the two regions and the global cooperation. There is hardly any convergence in the A2 and B2 scenarios.

\subsection{METHANE EMISSIONS PER CAPITA}

The total methane emission level per capita was very different in the four regions in 1990 (See Fig. 12). In each region different sources dominate: in OECD90 the energy sector, cattle (enteric fermentation and animal waste), and waste (landfills and sewage) are the primary sources. Comparable per capita emissions for the same sources dominate in REF, except for the fossil energy sector which are much higher than in OECD90. Hence the total per capita ends up one-third higher. In ASIA and ALM the role of fossil energy is much smaller, so this source of methane emissions is less important in these regions. The same goes for landfills in light of prevailing, uncontrolled waste disposal. As the vast majority of all rice paddies is located in ASIA, in this region only is rice growing a major source of methane. Cattle plays a limited role and hence overall methane emissions per capita in ASIA are relatively low, less than half of those in the OECD. In ALM, cattle-related emissions are relatively important (non-dairy cattle in LatinAmerica), together with biomass burning which is a minor source in all other regions.

In the Marker scenarios the trends differ between the four regions. In ASIA the compounded effect of lower rice related emissions per capita (higher yields; shifts in diet) and higher emissions from meat production and fossil energy result in relatively stable projection. In ALM, however, emissions per capita fall in all cases. In the OECD emissions decrease in $\mathrm{A} 1 \mathrm{~B}$ and $\mathrm{B} 1$ as the role of fossil energy declines and waste management practices improve. In $\mathrm{B} 2$ emissions remain close to the current level, while in the fossil fuel dominated A2 scenario emissions increase slightly. Only in this scenario do per capita emissions increase in all regions. The methane emissions in the REF region remain the highest in all scenarios.

\subsection{TOTAL GREENHOUSE GAS EMISSIONS PER CAPITA}

The total greenhouse gas emissions (based on GWP) per capita are shown in Fig. 13. Despite the non-carbon emissions, the overall trends for all greenhouse gases are rather similar to total carbon levels (see Fig. 11). In all scenarios the per capita emission in the IND region are above DEV levels. The 1990 gap between the two regions declines 


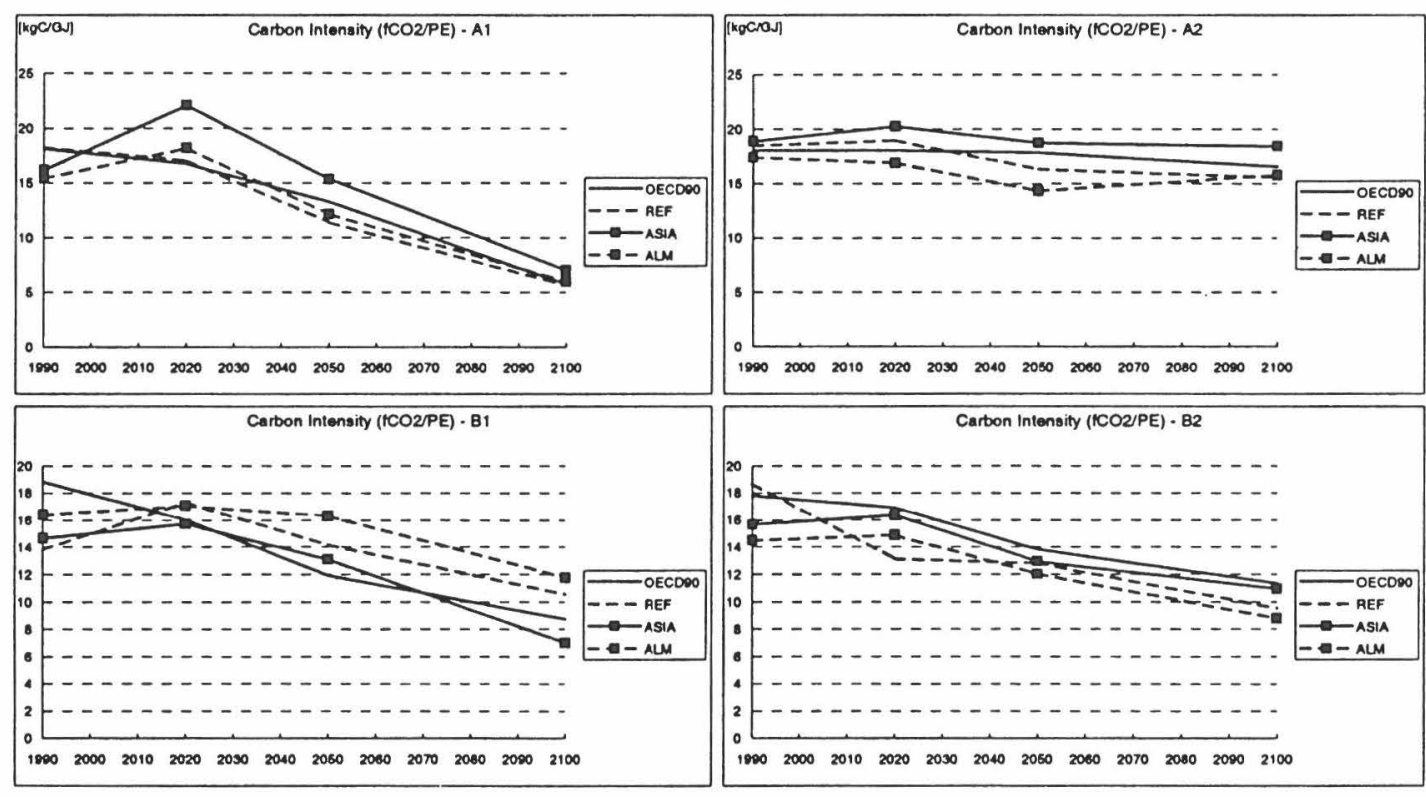

Fig. 10. Carbon intensity of Primary Energy. 


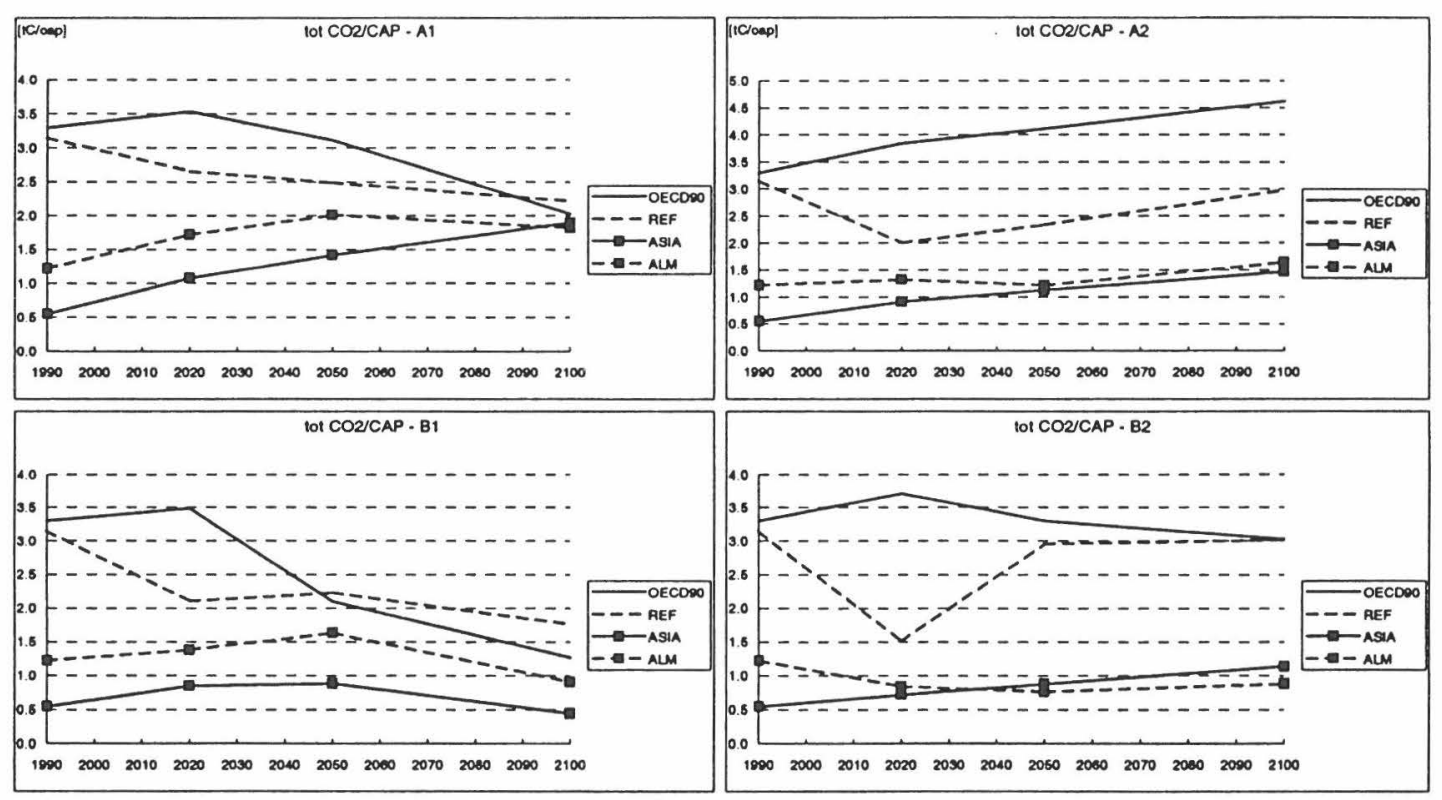

Fig. 11. Carbon emissions per Capita. 


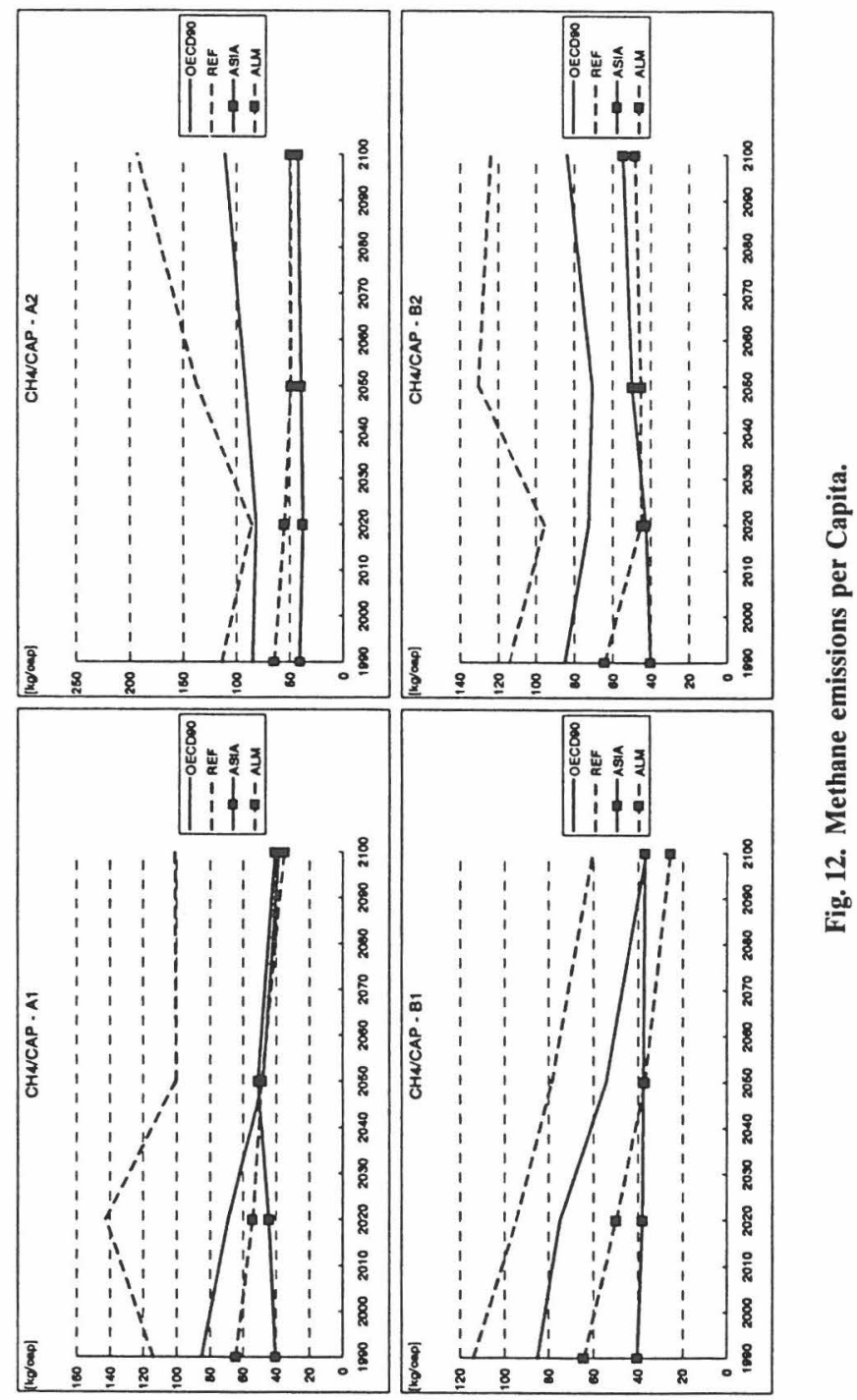




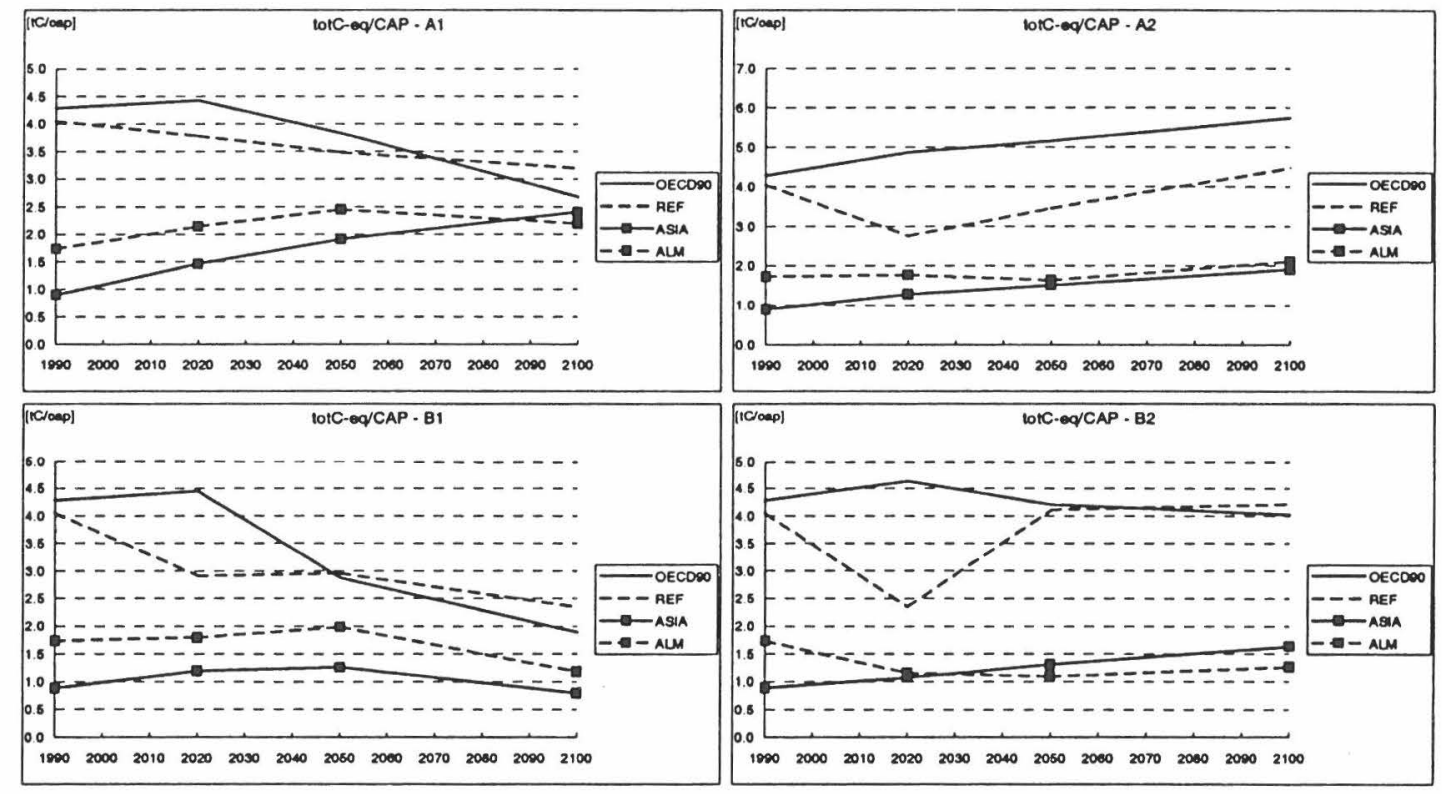

Fig. 13. GHG emissions per Capita. 
in the $\mathrm{A} 1$ and $\mathrm{B} 1$ scenario as a result of world convergence including exchange of efficient technologies. The two levels hardly converge in the other two "heterogeneous" scenarios.

\section{Conclusions}

Today the distribution of both affluence ("wealth") and of greenhouse gas emissions is very unbalanced between various world regions. In addition, the relative importance of individual gases and sources of emission differ from region to region. A common feature of all Marker scenarios is that the growth of both population and income is higher in the current developing countries (DEV) than in the industrialized countries (IND). Notwithstanding, levels of per capita income are very different across the scenarios and the degree of convergence between regions varies considerably. Very similar observations can be made with regard to greenhouse gas emissions: while today the DEV region accounts for about $46 \%$ of all emissions (measured by their GWP; excluding the Montreal gases), in 2100 no less than $67-76 \%$ of the global total is released in the region. At the same time the total income (measured on a MER basis) generated in the $\mathrm{DEV}$ regions rises from $16 \%$ in 1990 to $58-71 \%$ by 2100 , indicating that the relative emissions per unit of income (GDP) tend to converge over time.

When confronting the population size and the levels of affluence in the regions with the potential severity of climate change induced damages, the scenarios are very different. Assuming that higher population densities and lower income make regions more vulnerable for adverse climate change impacts, and that lower income create less favorable conditions for mitigation and/or adaptation measures, a rough ranking of the four Marker scenarios can be made as follows in Table 4.

It must be noted that this ranking does not take into account that the perception of the situation can very well differ also between scenarios. In other words, the willingness to accept climate impacts and/or the willingness to pay to mitigate or adapt is not independent from the scenario and can lead to quite different appreciation than the more objective ranking given in the table above.

In addition it can be argued that more divided worlds with more pronounced disparities in income between the IND and DEV regions (scenarios A2 and B2) make for less favorable conditions to develop and implement efficient and effective cooperative strategies to mitigate and/or adapt to climate change.

Fossil carbon remains the dominant source of greenhouse gas emissions. Its relative share increases as other $\mathrm{CO}_{2}$ emissions decline from their current high level, the haloge-

TABLE 4

Rough Ranking of the Four Marker Scenarios

\begin{tabular}{lclll}
\hline Marker & Potential damage $^{\mathrm{a}}$ & Population $^{\mathrm{h}}$ & \multicolumn{1}{c}{ Income $^{\mathrm{c}}$} & Ranking $^{\text {M }}$ \\
\hline A1 & Medium & Low & Very High & Fair \\
& $(17)$ & $(1.4 / 5.6)$ & $(75 / 107 / 67)$ & \\
A2 & High & High & Very Low & Poor \\
& $(37)$ & $(2.2 / 12.9)$ & $(16 / 47 / 11)$ & \\
B1 & Low & Low & Medium-High & Good \\
& $(8)$ & $(1.4 / 5.7)$ & $(47 / 73 / 40)$ & \\
B2 & Medium & Medium & Low & Medium \\
& $(19)$ & $(1.3 / 9.1)$ & $(23 / 54 / 18)$ & \\
\hline
\end{tabular}

'Denoted by the total, global GHG emission level, measured by GWP in 2100 (in Gt C-eq.).

'Billion in IND/DEV.

'In 1.000 US\$ per capita (World/IND/DEV). 
nated compounds never return to their currently significant share of $15 \%$ (including Montreal gases), and land-use related methane and nitrous oxide emissions increase at most in line with population, so far less than economic output and energy demand. This development strongly favors a primary focus on strategies to mitigate carbon emissions.

A specific issue is presented by the role of sulfur. Contrary to many earlier scenarios, including the majority of the IPCC/IS92 cases, the Markers all assume that in all regions sooner or later, and to various degrees, sulfur emissions are controlled. As sulfur plays a role in cooling of the atmosphere through formation of sulfate aerosols, their abatement constitutes a relative warming effect. The short atmospheric residence time and thus poor mixing of sulfur aerosols imply that these effects are very local and their magnitude varies widely (Schlesinger et al. in this special issue).

The authors are grateful to Cees Volkers (ECN) for collection and processing of the data and Remko Ybema (ECN) for his useful comments on the draft.

\section{References}

1. Alcamo, J., Bouwman, A., Edmonds, J., Grübler, A., Morita, T., and Sungandhy, A.: An Evaluation of the IPCC IS92 Emissions Scenarios, in Climate Change 1994, Radiative Forcing of Climate Change and An Evaluation of the IPCC IS92 Emissions Scenarios. Cambridge University Press, Cambridge, UK, 1995, pp. 233-304.

2. Alcamo, J., and Nakicenovic, N.: Mitigation and Adaptation Strategies for Global Change. Kluwer Academic Publishers, Dordrecht, The Netherlands, 1998, Vol. 3, Nos. 2-4 in series.

3. Morita, T., Matsuoka, Y., Penna, I., and Kainuma, M.: Global Carbon Dioxide Emission Scenarios and Their Basic Assumptions: 1994 Survey. CGER-1011-94. Center for Global Environmental Research, National Institute for Environmental Studies, Tsukuba, Japan, 1994.

4. U.S. E.P.A. (Environmental Protection Agency): Policy Options for Stabilizing Global Climate: Report to Congress, Washington. DC, 1990.

5. Alcamo, J. (ed.): IMAGE 2.0: Integrated Modelling of Global Change. Kluwer Academic Publishers, Dordrecht, the Netherlands, 1994.

6. Mori, S., and Takahashi, M.: An Integrated Assessment Model for the Evaluation of New Energy Technologies and Food Productivity, International Journal of Global Energy Issues 11(1-4), 1-18 (1999).

7. Messner, S., and Strubegger, M.: User's Guide for MESSAGE III. WP-95-69, International Institute for Applied Systems Analysis, Laxenburg, Austria, 1995, pp. 155.

8. Edmonds, J., Wise, M., Pitcher, H., Richels, R., Wigley, T., and MacCracken, C.: An Integrated Assessment of Climate Change and the Accelerated Introduction of Advanced Energy Technologies: An Application of MiniCAM 1.0, Mitigation and Adaptation Strategies for Global Change 1(4), 311-339 (1996).

9. Watson, R., Zinyowera, M. C., and Moss, R. (eds.): Climate Change 1995. Impacts, Adaptations and Mitigation of Climate Change: Scientific Analyses. Cambridge University Press, Cambridge, UK, 1996, pp. 861.

10. Schimel, D., Alves, D., Enting, I., Heimann, M., Joos, F., Raynaud, D., Wigley, T., Prather, M., Derwent, R., Ehhalt, D., Fraser, P., Sanhueza, E., Zhou, X., Jonas, P., Charlson, R., Rodhe, H., Sadasivan, S., Shine, K. P., Fouquart, Y., Ramaswamy, V., Solomon, S., Srinivasan, J., Albritton, D., Derwent, R., Isaksen, I., Lal, M., and Wuebbles, D.: Radiative Forcing of Climate Change, in Climate Change 1995-The Science of Climate Change, IPCC. Cambridge University Press, Cambridge, UK, 1995.

11. Hansen, J., Sato, M., Glascoe J., and Ruedy, R.: A Common-Sense Climate Index: Is Climate Changing Noticeably?, Proc. Natl. Acad. Sci. USA 95, 4115-4120 (1998).

12. Dlugokencky, E. J., Masarie, K. A., Lang P. M., and Tans, P. P.: Continuing Decline in the Growth Rate of the Atmospheric Methane Burden. Nature 393, 447-450 (1998).

13. Etheridge, D. M., Steele, L. P., Francy, R. J., and Langerfelds, R. L.: Atmospheric Methane Between 1000 $\mathrm{AD}$ and Present: Evidence of Atmospheric Emissions and Climatic Variability, J. Geophysical Res. 103. D13 (1998).

14. Houghton, J. T., Meira Filho, L. G., Bruce, J., Lee, Hoesung, Callander, B. A., Haites, E., Harris, N., and Maskell, K. (eds.): Climate Change 1994: Radiative Forcing of Climate Change and an Evaluation of the IPCC IS92 Emissions Scenarios. Cambridge University Press, Cambridge, UK, 1995, pp. 339.

15. Houghton, J. T., Meira Filho, L. G., Callander, B. A., Harris, N., Kattenberg, A., and Maskell, K. (eds.): Climate Change 1995. The Science of Climate Change, Contribution of Working Group I to the Second 
Assessment Report of the Intergovernmental Panel on Climate Change, Cambridge University Press. Cambridge, UK, 1996.

16. WMO/UNEP (World Meteorological Organisation and United Nations Environment Programme): Scientific Assessment of Ozone Depletion: 1998. WMO Global Ozone Research \& Monitoring. World Meteorological Organisation (WMO), Geneva, Switzerland, 1998.

17. Kroeze, C.: Fluorocarbons and SF6, Global Emission Inventory and Options for Control. RIVM report 773001007. Bilthoven, the Netherlands, 1995.

18. Hammitt, J. K., Camm, F., Connell, P. S., Mooz, W. E., Wolf, K. A., Wuebbles, D. J., and Bamezai, A.: Future Emission Scenarios for Chemicals That May Deplete Stratospheric Ozone, Nature 330, 711-716 (1987).

19. AFEAS (Alternative Fluorocarbons Environmental Acceptability Study): Production. Sales and Atmosphere Release of Fluorocarbons Through 1997. Washington, DC, 1998.

20. U.S. Geological Survey: Mineral Commodities Information. http://minerals.er.gove/minerals/pubs/commodity/, 1998.

21. Victor, D. G., and MacDonald. G. J.: A Model for Estimating Future Emissions of Sulfur Hexafluoride and Perfluorocarbons. IR-98-053, International Institute for Applied Analysis, Laxenburg. Austria, 1998, pp. 33.

22. Olivier, J. G. J., Bouwman, A. F., van der Maas, C. W. M., Berdowski, J. J. M., Veldt, C., Bloos, J. P. J., Visschedijk, A. J. H., Zandveld P. Y. J., and Haverlag, J. L.: Description of EDGAR Version 2.0: A Set of Global Emission Inventories of Greenhouse Gases and Ozone-Depleting Substances for All Anthropogenic and Most Natural Sources on a Per Country Basis and on $1^{\circ} \times 1^{\circ}$ Grid. Report 771060002 , National Institute of Public Health and the Environment, Bilthoven, the Netherlands, 1996.

23. Benkovitz, C. M., Scholtz, M. T., Pacyna, J., Tarrason, L., Dignon, J., Voldner, E. C., Spiro, P. A., Logan, J. A., and Graedel, T. E.: Global Gridded Inventories of Anthropogenic Emissions of Sulfur and Nitrogen, Journal of Geophysical Research 101(D22), 29, 239-29, 253 (1996).

24. WMO (World Meteorological Organisation: Global Acid Deposition Assessment, in WMO Global Atmospheric Watch, No. 16. Whelpdate, D. M., and M. S. Kaiser (eds.), World Meterorological Organisation (WMO), Geneva, Switzerland, 1997.

25. Smith, S. J., Pitcher, H. M., Wise, M., and Wigley, T. M. L.: Future Sulfur Dioxide Emissions. Report, NCAR, Boulder, CO, USA, 1998.

26. Grübler, A.: Emissions Scenarios Database and Review of Scenarios. Mitigation and Adaptation Strategies for Global Change (3)2-4, 383-418 (1998).

27. Foell, W., Amann, M., Carmichael, G., Hettelingh, J.-P., Hordijk, L., and Dianwu, Z.: Rains Asia: An Assessment Model for Air Pollution in Asia. Report on the World Bank sponsored project "Acid Rain and Emission Reductions in Asia", World Bank, Washington, DC, 1995.

28. Akimoto, H., and Narita, $\mathrm{H}$.: Distribution of $\mathrm{SO} 2, \mathrm{NOX}$, and $\mathrm{CO} 2$ Emissions from Fuel Combusion and Industrial Activities in Asia with 1x1 Degree Resolution. Atmospheric Environment 28(2), 213-225 (1994).

29. Kato, N.: Analysis of Structure of Energy Consumption and Dynamics of Emission of Atmospheric Species Related to Global Environmental Change (SOx, NOx, CO2) in Asia. Atmospheric Environment 30(5), 757-785 (1996).

30. Pepper, W. J., Leggett, J., Swart, R., Wasson, J., Edmonds, J., and Mintzer, I.: Emissions Scenarios for the IPCC. An Update: Assumptions, Methodology, and Results. Support Document for Chapter A3, in Climate Change 1992: Supplementary Report to the IPCC Scientific Assessment. Houghton, J. T., Callandar B. A., and Varney S. K., (eds.), Cambridge University Press, Cambridge, UK, 1992.

31. ECE (UN Economic Commission for Europe): Anthropogenic Emissions of Sulfur 1980 to 2010 in the ECE Region. EB.AIR/GE.1/1997/3 and Addendum 1.ECE, Geneva, Switzerland, 1997.

32. Sinton, J. E. (ed.): China Energy Databook. LBL-32822 Rev. 4 UC-900, Lawrence Berkeley National Laboratory, University of California, Berkeley, CA., USA, 1996.

33. Dadi, Z., and Huaqing, X.: Estimation of Sulfur Dioxide Emissions in China in 1990 and 1995. Energy Research Institute, Beijing, China, 1998.

34. Dignon, J. and Hameed, S.: Emissions of Nitrogenand Sulfuroxides from 1860 to 1989, Journal of the Air and Waste Management Association 39(2), 180-186 (1989).

35. Spiro, P. A., Jacobs D. J., and Logan, J. A.: Global Inventory of Sulfur Emissions with $1 \times 1$ Degree Resolution, J. Geophys. Res. 97, 6023-6036 (1992).

36. Amann, M., Bertok, I., Cofala, J., Gyarfas, F., Heyes, C., Klimont, Z., Makowski, M., Schoepp, W., and Shibayev, S.: Cost-Effective Control of Acidification and Ground-Level Ozone. Second interim report to the European Commission, DGXI, International Institute of Applied Systems Analysis (IIASA), Laxenburg, Austria, 1996. 


\section{Ordering Information}

Orders must include the publication number and should be sent to the Publications Department, International Institute for Applied Systems Analysis, A-2361 Laxenburg, Austria.

Telephone: +432236807

Telefax: +432236 71313

E-mail: molina@iiasa.ac.at

A full list of IIASA publications is available at www.iiasa.ac.at 
International Institute for Applied Systems Analysis

A-2361 Laxenburg, Austria 